IUCrJ

ISSN 2052-2525

BIOLOGY|MEDICINE

Received 16 July 2018

Accepted 1 October 2018

Edited by Z.-J. Liu, Chinese Academy of Sciences, China

₹ These authors contributed equally to this work.

Keywords: viral PARP-1-interacting protein; open reading frame 49; poly(ADP-ribose) polymerase 1 ; murine gammaherpesvirus 68; Kaposi's sarcoma-associated herpesvirus; structure determination; X-ray crystallography.

PDB reference: viral PARP-1-interacting protein, $6 \mathrm{a} 4 \mathrm{v}$

Supporting information: this article has supporting information at www.iucrj.org

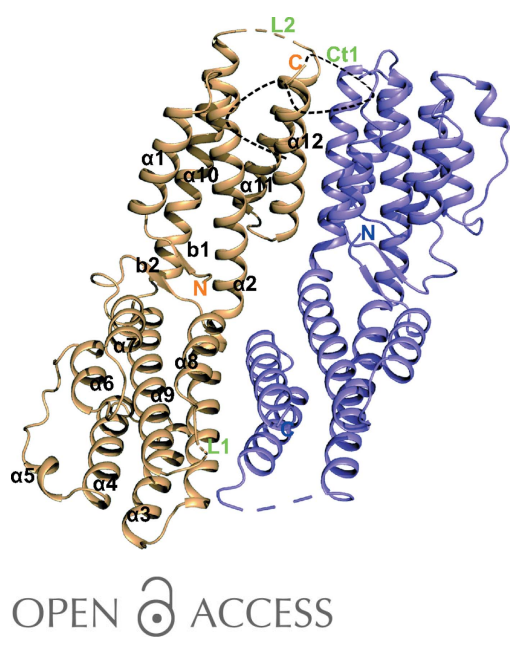

\section{Structure-based mechanism of action of a viral poly(ADP-ribose) polymerase 1-interacting protein facilitating virus replication}

\author{
Woo-Chang Chung, ${ }^{a} \ddagger$ Junsoo Kim, ${ }^{b} \neq$ Byung Chul Kim, ${ }^{\text {a Hye-Ri Kang, }}{ }^{a}$ \\ JongHyeon Son, ${ }^{\mathrm{b}}$ Hosam Ki, ${ }^{\mathrm{b}}$ Kwang Yeon Hwang ${ }^{\mathrm{b} *}$ and Moon Jung Song ${ }^{\mathrm{a} *}$
}

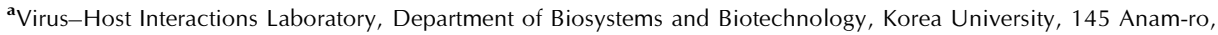
Seongbuk-gu, Seoul 02841, Republic of Korea, and ${ }^{\mathbf{b}}$ Structural Proteomics Laboratory, Department of Biosystems and Biotechnology, Korea University, 145 Anam-ro, Seongbuk-gu, Seoul 02841, Republic of Korea. *Correspondence e-mail: chahong@korea.ac.kr, moonsong@korea.ac.kr
\end{abstract}

Poly(ADP-ribose) polymerase 1 (PARP-1), an enzyme that modifies nuclear proteins by poly(ADP-ribosyl)ation, regulates various cellular activities and restricts the lytic replication of oncogenic gammaherpesviruses by inhibiting the function of replication and transcription activator (RTA), a key switch molecule of the viral life cycle. A viral PARP-1-interacting protein (vPIP) encoded by murine gammaherpesvirus 68 (MHV-68) orf49 facilitates lytic replication by disrupting interactions between PARP-1 and RTA. Here, the structure of MHV-68 vPIP was determined at $2.2 \AA$ resolution. The structure consists of 12 $\alpha$-helices with characteristic $\mathrm{N}$-terminal $\beta$-strands $(\mathrm{N} \beta)$ and forms a V-shapedtwist dimer in the asymmetric unit. Structure-based mutagenesis revealed that $\mathrm{N} \beta$ and the $\alpha 1$ helix (residues 2-26) are essential for the nuclear localization and function of vPIP; three residues were then identified (Phe5, Ser12 and Thr16) that were critical for the function of vPIP and its interaction with PARP-1. A recombinant MHV-68 harboring mutations of these three residues showed severely attenuated viral replication both in vitro and in vivo. Moreover, ORF49 of Kaposi's sarcoma-associated herpesvirus also directly interacted with PARP-1, indicating a conserved mechanism of action of vPIPs. The results elucidate the novel molecular mechanisms by which oncogenic gammaherpesviruses overcome repression by PARP-1 using vPIPs.

\section{Introduction}

Poly(ADP-ribose) polymerase 1 (PARP-1) is a nuclear enzyme that catalyzes poly(ADP-ribosyl)ation (PARylation) of target proteins by transferring the ADP-ribose unit from $\mathrm{NAD}^{+}$ (Rouleau et al., 2010). PARP-1 activity is involved in several important cellular functions such as differentiation, proliferation, malignant transformation and DNA damage repair (Kim et al., 2005; Ko \& Ren, 2012; Luo \& Kraus, 2012; Gibson \& Kraus, 2012). Of note, PARP-1 activity has been implicated in virus-host conflicts either positively or negatively (Gupte et al., 2017; Ko \& Ren, 2011, 2012; Rom et al., 2015; Dandri et al., 2002). For example, the replication of retroviruses such as human immunodeficiency virus 1 and human T-lymphotropic virus 1 is affected by PARP-1 activity at the steps of genome integration, genome replication and viral gene transcription (Zhang et al., 2002; Kameoka et al., 1999, 2005; Bueno et al., 2013; Ha et al., 2001; Rom et al., 2015). PARP-1 modulates hepatitis B virus replication and DNA integration into the host chromosome (Ko \& Ren, 2011; Dandri et al., 2002). PARP-1 is also associated with herpesvirus replication; herpes 
simplex virus 1 activates PARP-1 during replication (Grady et al., 2012).

The roles of PARP-1 in oncogenic gammaherpesviruses, including Epstein-Barr virus (EBV), Kaposi's sarcomaassociated herpesvirus (KSHV) and murine gammaherpesvirus 68 (MHV-68), have been studied in more detail and involve the suppression of lytic replication and reactivation (Gwack et al., 2003; Ohsaki et al., 2004; Wang et al., 2008; Lupey-Green et al., 2017; Mattiussi et al., 2007; Martin et al., 2016; Tempera et al., 2010). As a key switch molecule of the gammaherpesvirus life cycle, a protein called replication and transcription activator (RTA) performs an essential function in lytic replication and reactivation from latency (Sun et al., 1998; Lukac et al., 1998, 1999). In gamma-2 herpesviruses (rhadinoviruses), including KSHV and MHV-68, PARP-1 PARylates RTA and inhibits its transactivation, resulting in the overall suppression of viral lytic replication (Gwack et al., 2003). In EBV, a gamma-1 herpesvirus (lymphocryptovirus), the binding of PARP-1 to a lytic promoter also represses viral reactivation (Lupey-Green et al., 2017).

Meanwhile, gammaherpesviruses encode viral proteins to overcome negative regulation by PARP-1; for example, viral processivity factors in KSHV and MHV-68 induce the degradation of PARP-1 in a proteasome-dependent manner, thus promoting lytic replication (Cheong et al., 2015). In MHV-68, ORF49, a tegument protein, facilitates RTA-mediated transactivation by interacting with PARP-1, thereby disrupting interactions between RTA and PARP-1 (Lee et al., 2007; Noh et al., 2012). ORF49 homologs from human gammaherpesviruses such as Epstein-Barr virus BRRF1 (also called Na) and KSHV ORF49 have been reported to promote viral lytic replication by cooperating with RTA (González et al., 2006; Hong et al., 2004), although it is not known whether they share the molecular mechanisms of PARP-1 interaction and inhibition. Yeast two-hybrid screening of EBV viral proteins using a human cDNA library revealed that EBV BRRF1 interacts with PARP-4, a homolog of PARP-1 (Calderwood et al., 2007), while the direct inhibition of RTA by PARP-1 has not been reported.

Here, we show a direct physical interaction of MHV-68 ORF49 with PARP-1 in solution and propose calling this protein viral PARP-1-interacting protein (vPIP). We determined the X-ray crystal structure of vPIP at $2.2 \AA$ resolution. The vPIP protein consists of $12 \alpha$-helices and two $\beta$-strands and forms a V-shaped-twist dimer in the asymmetric unit. We performed structure-based mutagenesis to identify domains and residues of vPIP that are crucial for subcellular localization, protein-protein interactions and the functional activity of vPIP. The functional significance of crucial residues was next examined in the context of virus replication both in vitro and in vivo using a recombinant virus harboring the mutations. Finally, the protein encoded by KSHV orf49 (ORF49 $\left.9_{\mathrm{KSHV}}\right)$ was found to interact with PARP-1, thereby relieving PARP-1 repression of RTA. Based on the structural information, this study highlights the conserved molecular mechanism by which vPIPs of oncogenic gammaherpesviruses facilitate viral replication in vitro and in vivo.

\section{Materials and methods}

\subsection{Purification of proteins in bacteria}

The genomic regions for MHV-68 vPIP and ORF49 ${ }_{\mathrm{KSHV}}$ were cloned into pET-22b or pET-28a plasmids (Novagen), respectively, using gene-specific primers (Supplementary Table S1). MHV-68 vPIP and ORF49 ${ }_{\mathrm{KsHV}}$ were overexpressed in Escherichia coli Rosetta 1 strain and BL21 strain (Novagen) at $18^{\circ} \mathrm{C}$ after induction with $0.5 \mathrm{~m} M$ isopropyl $\beta$-D-1-thiogalactopyranoside (IPTG). The proteins were purified by NiNTA affinity chromatography. A linear concentration gradient was applied to elute the product at a flow rate of $5 \mathrm{ml} \mathrm{min}{ }^{-1}$ in a buffer consisting of $50 \mathrm{~m} M$ HEPES pH 7.5, $150 \mathrm{~m} M \mathrm{NaCl}$, $5 \mathrm{~m} M \beta$-mercaptoethanol, $500 \mathrm{~m} M$ imidazole. The proteins were further purified by ion-exchange chromatography with a linear $\mathrm{NaCl}$ gradient and were concentrated using Amicon Ultra centrifugal filters (Merck Millipore). A size-exclusion chromatography step was next performed on a Superdex 200 26/60 column (GE Healthcare) equilibrated with final buffer (50 $\mathrm{m} M$ HEPES pH 7.5, $100 \mathrm{mM} \mathrm{NaCl}, 1 \%$ glycerol, $10 \mathrm{~m} M$ dithiothreitol). Finally, the proteins were concentrated to $15 \mathrm{mg} \mathrm{ml}^{-1}$ for crystallization and surface plasmon resonance analysis using Amicon Ultra centrifugal filters and stored at $-80^{\circ} \mathrm{C}$.

\subsection{Crystallization}

Crystals were grown using a sitting-drop vapor-diffusion screen in which $0.5 \mu \mathrm{l}$ protein sample was mixed with an equal volume of screening solution from the Crystal Screen kit in 96-well Intelli-Plates (Hampton Research) and using standard hanging-drop vapor-diffusion techniques. An initial crystallization hit was found in a saturating solution of $0.1 \mathrm{M}$ Tris- $\mathrm{HCl} \mathrm{pH} \mathrm{8.2,0.33M}$ sodium/potassium tartrate, $0.5 \%$ polyethylene glycol 5000 monomethyl ether. Crystals were obtained by mixing $1 \mu \mathrm{l}$ protein solution with $1 \mu \mathrm{l}$ reservoir solution. The crystals were transferred into reservoir solution containing $20 \%$ ethylene glycol before flash-cooling in liquid nitrogen.

\subsection{Structure determination}

Diffraction data were collected on beamline BL1A at KEK, Photon Factory, Japan and the data were processed using SCALEPACK and DENZO from the HKL-2000 software package. The crystal belonged to space group $P 3_{2} 21$, with unitcell parameters $a=b=134.179, c=157.158 \AA, \alpha=\beta=90$, $\gamma=120^{\circ}$. There are two molecules in the asymmetric unit. Single-wavelength anomalous dispersion (SAD) data were collected from selenomethionine-labeled vPIP crystals at an inflection wavelength of $0.9792 \AA$ and were processed using HKL-2000. The PHENIX AutoSol program was used for phasing (Adams et al., 2010). The initial model was manually rebuilt in Coot and refined using CCP4i (Winn et al., 2011). The final refinement was conducted using phenix.refine in PHENIX. The final model had $R_{\text {work }}=23.6 \%$ and $R_{\text {free }}=$ $27.3 \%$. The description of the crystal structure was prepared in 
PyMOL (DeLano, 2001). Data-collection and refinement statistics are summarized in Supplementary Table S2.

\subsection{Multi-angle light-scattering assay}

Proteins in $50 \mathrm{~m} M$ HEPES pH 7.5 with $100 \mathrm{~m} M \mathrm{NaCl}$ were studied by analytical size-exclusion chromatography on a WTC-050S5 column (Wyatt Technology) and directly flowed into a Wyatt DAWN HELEOS II light-scattering detector and a Wyatt Optilab T-rEX refractive-index detector (Wyatt Technology). The column was employed to determine the average molecular mass of the elution peak from the Rayleigh scattering intensity as a function of the scattering index (LSR) and the buffer scattering index (dRI) using ASTRA 6 (Wyatt Technologies) (Trathnigg, 1995).

\subsection{Surface plasmon resonance (SPR) binding assays}

SPR assays were conducted on a Biacore T-100 instrument (GE Healthcare). To measure interactions between PARP-1 and vPIP, the surface of the sensor chip CM5 (GE Healthcare) has a carboxymethylated dextran matrix covalently attached to a surface coating on a gold film. Kinetic analysis was carried out at a flow rate of $30 \mu \mathrm{min} \mathrm{min}^{-1}$. The standard running buffer was HBS-EP [10 m $M$ HEPES pH 7.4, $150 \mathrm{~m} M \mathrm{NaCl}, 3 \mathrm{~m} M$ EDTA, $0.005 \%(v / v)$ surfactant P20; GE Healthcare]. The results were processed using the Biacore T-100 analysis software. His-tagged mouse PARP-1 protein (Sino Biological) was reconstituted in a sterile buffer consisting of $20 \mathrm{~m} M$ Tris $\mathrm{pH}$ 8.0, $500 \mathrm{~m} M \mathrm{NaCl}, 10 \%$ glycerol, $0.1 \mathrm{~m} M$ tris(2-carboxyethyl) phosphine hydrochloride. Capturing the purified His-tagged mouse PARP-1 protein in flow cell 2 was performed by injecting a $200 \mu \mathrm{g} \mathrm{ml}^{-1}$ protein solution for $1 \mathrm{~h}$ at a flow rate of $5 \mu \mathrm{min}^{-1}$. Flow cell 1 served as a reference for the substrate in terms of nonspecific binding, drift and the bulk refractive index. Compounds were assayed in single-cycle kinetics mode in five-point and six-point twofold concentration series from 0.1 to $3.45 \mu M$ for MHV-68 vPIP and from 0.22 to $7.12 \mu M$ for ORF49 ${ }_{\mathrm{KSHV}}$. Data were processed and fitted to a 1:1 binding model in the Biacore T100 evaluation software to determine the binding kinetic rate constants $k_{\mathrm{a}}$ (on rate) and $k_{\mathrm{d}}$ (off rate), and the equilibrium dissociation constant $K_{\mathrm{d}}$.

\subsection{Cell culture and virus}

HEK293T, HeLa, BHK21 and Vero cells were cultured in complete Dulbecco's modified Eagle's medium (HyClone) containing $10 \%$ fetal bovine serum (FBS; HyClone) and supplemented with $100 \mathrm{U} \mathrm{ml}^{-1}$ penicillin and $100 \mu \mathrm{g} \mathrm{ml}^{-1}$ streptomycin (HyClone). The MHV-68 virus was originally purchased from the American Type Culture Collection (ATCC; catalog No. VR1465). The amplified or reconstituted viruses were titrated by plaque assays on Vero cells overlaid with $1 \%$ methylcellulose (Sigma) in the normal growth medium.

\subsection{Plasmid}

MHV-68 vPIP mutant constructs were cloned into the pENTR vector (Invitrogen) using the primers listed in
Supplementary Table S1. The entry clones were further transferred to the desired destination vectors containing additional sequences to generate MYC-tagged, FLAG-tagged or GFP-tagged vPIP mutants using the Gateway technology (Invitrogen). FLAG-tagged vPIP $\Delta \mathrm{N}+\mathrm{NLS}_{\mathrm{SV} 40}$ was generated by inserting a classical nuclear localization signal (NLS) from the SV40 large T-antigen (PKKKRKV; Ng et al., 2018). A PARP-1 expression construct (pCMV5-PARP-1) was a kind gift from Dr W. Lee Kraus at the University of Texas Southwestern Medical Center (Dallas, Texas, USA). FLAG-tagged and GFP-KSHV ORF49 constructs were generated as described previously (Chung et al., 2015).

\subsection{Luciferase reporter assays}

The Luciferase Reporter Assay Kit (Promega) was applied to measure the activity of the RTA promoter (Rp-LUC) or the RTA-responsive promoter (M3p-LUC) (Lukac et al., 1999; Chung et al., 2015). To test the functionality of vPIP mutants in terms of the promoter activity, HEK293T cells were transfected using polyethylenimine $\left(1 \mathrm{mg} \mathrm{ml}^{-1}\right.$; Sigma) with a reporter construct, an RTA expression plasmid, a $\beta$-galactosidase ( $\beta$-gal) expression plasmid and a vPIP mutant plasmid, as described previously (Boussif et al., 1995). $26 \mathrm{~h}$ post-transfection, the cells were harvested and analyzed by the luciferase reporter assays according to the manufacturer's instructions. Each transfection for the reporter assays was performed in triplicate. In all of the assays, luminescence from the reporters was normalized to the activity of $\beta$-galactosidase.

\subsection{Creation of the MHV-68 vPIP $\mathrm{ml}$ and vPIP $\mathrm{mI}-\mathrm{MR}$ recombinant viruses}

The recombinant MHV-68 BAC plasmids expressing the vPIP $\mathrm{mI}$ and vPIP mI-MR viruses were generated by a REDmediated recombination method from BAC-containing $E$. coli cells (GS1783; Tischer et al., 2006; Yu et al., 2000). Briefly, we generated PCR template fragments containing kanamycinI-SceI from pEntransposon-KanR (STM vector, Finnzyme) with the forward primer 5'-AAGCCACGTTGTGTC-3' and the reverse primer $5^{\prime}$-ATTACCCTGTTATCCCTATTTTCG ACCGAATAAAG-3'. Electroporation of the kanamycinI-SceI-containing PCR fragment was used to transfect GS1783 cells. After a selection procedure, positive clones were confirmed by PCR screening and sequencing. To excise the virus genome from the BAC sequence, vPIP $\mathrm{mI}$ or vPIP mIMR BAC DNA was transfected using Lipofectamine Plus (Invitrogen) with a Cre expression plasmid into BHK21 cells $\left(5 \times 10^{5}\right)$ in six-well culture plates. The genome integrity of the reconstituted virus was verified by restriction-enzyme digestion.

\subsection{Quantitative real-time PCR}

Infected BHK21 cells, homogenized lung samples or splenocytes from infected mice were lysed overnight in a buffer consisting of $20 \mathrm{~m} M$ Tris- $\mathrm{HCl} \mathrm{pH}$ 7.5, $10 \mathrm{~m} M$ EDTA, $100 \mathrm{~m} M \mathrm{NaCl}, 0.5 \%$ SDS with $500 \mu \mathrm{g} \mathrm{ml}^{-1}$ proteinase $\mathrm{K}$, and viral genomic DNAs were isolated by the phenol:chloroform: 
isoamyl alcohol [25:24:1(v:v:v)] extraction method. M1 locusspecific primers (forward, 5'-CCTGGCCATGGTTACATAC TC-3'; reverse, 5'-GGAACATAATCCATAAGCAGGGT-3') were used to determine the copy numbers of viral genomic DNAs (Rickabaugh et al., 2005). Real-time PCR was carried out on a Rotor-Gene Q real-time PCR detection system

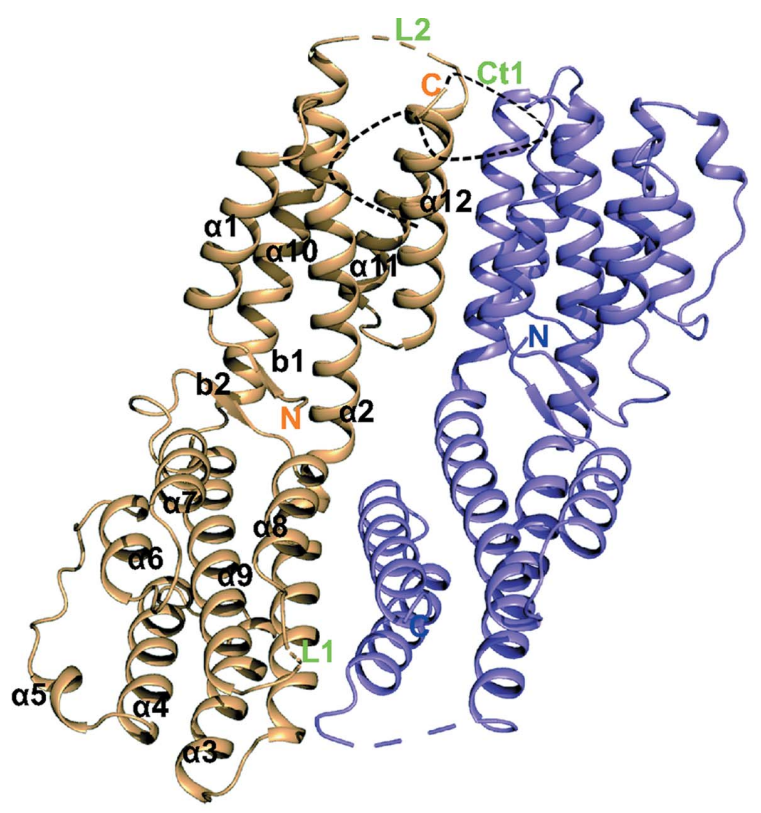

$(a)$

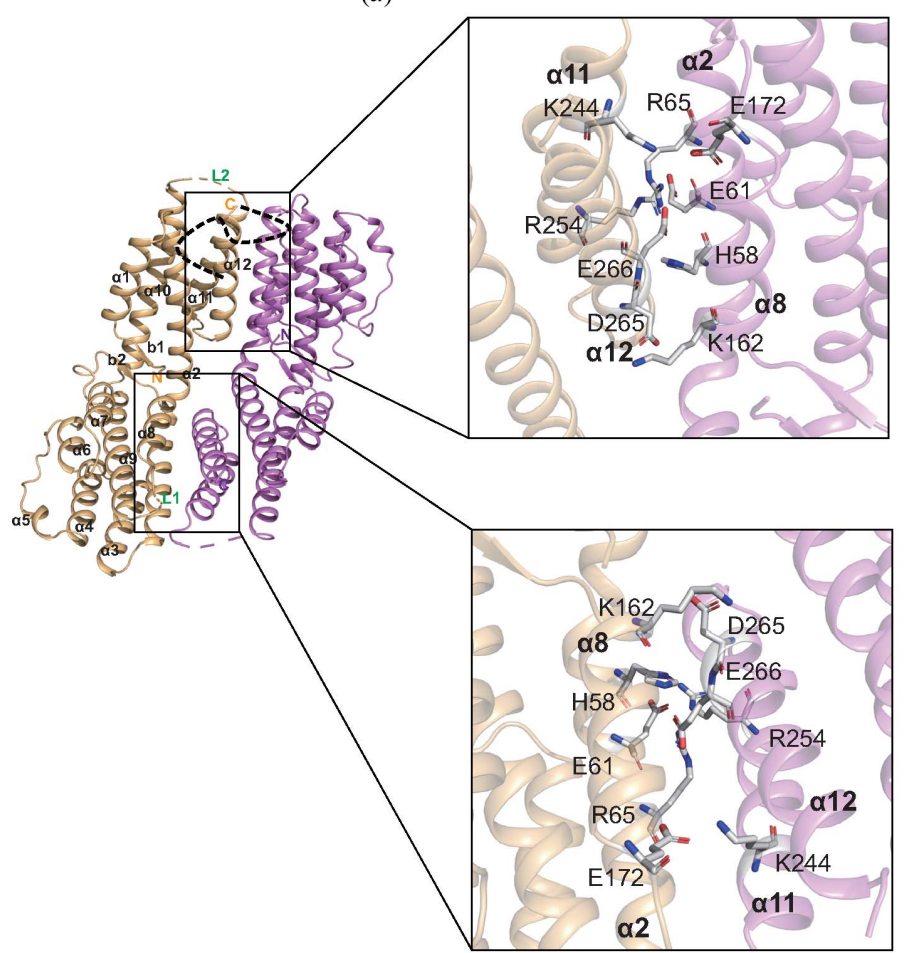

(c)

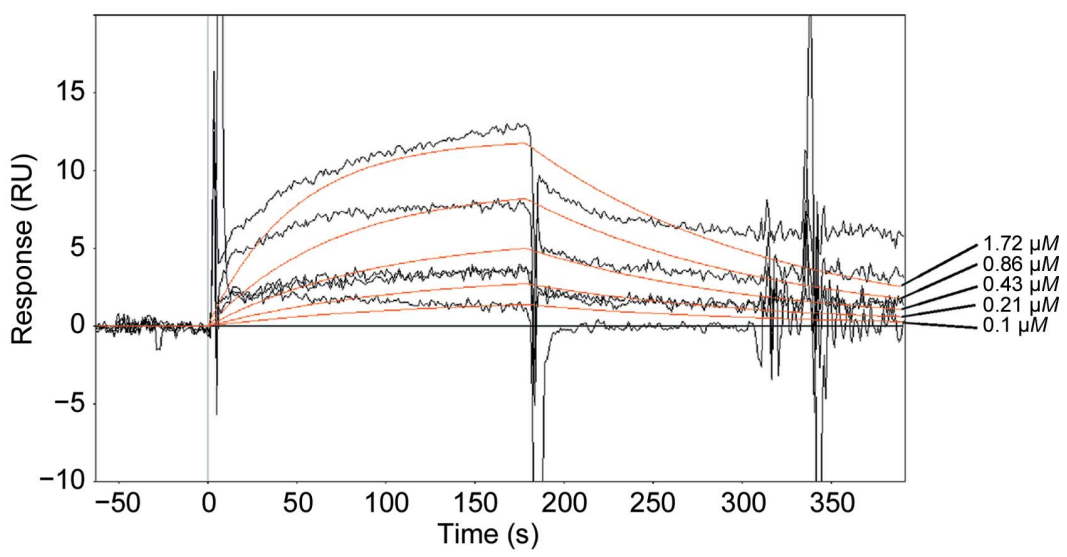

(b)

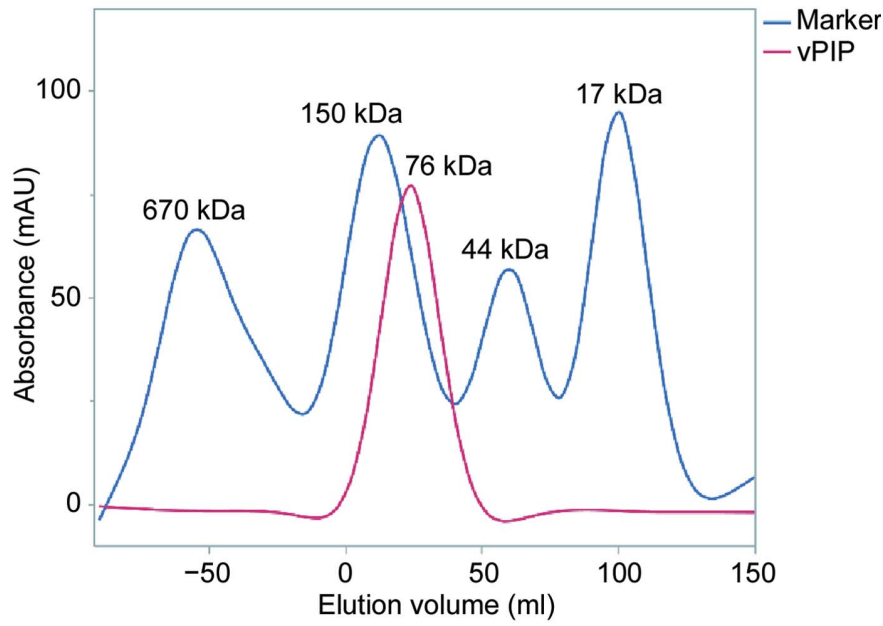

(d)

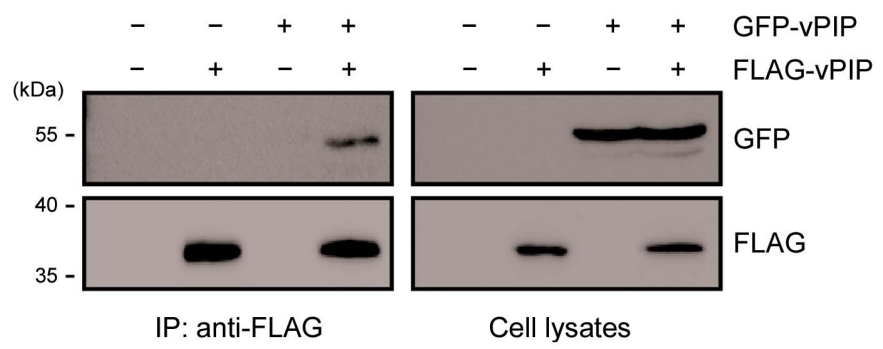

(e)

Figure 1

Overall structure and characterization of MHV-68 vPIP. (a) Crystal structure representation of MHV-68 vPIP. vPIP forms a dimer in the asymmetric unit with space group $P 3_{2} 21$. The crystal structure is shown with secondary structure that includes $12 \alpha$-helices and two $\beta$-strands. The dotted lines indicate the disordered loops (L1, L2 and Ct1). The chain $A$ helix bundle is shown in light orange and the chain $B$ helix bundle is shown in violet. (b) SPR analysis of vPIP with PARP-1. The vPIP protein was injected at five concentrations $(1.72,0.86,0.43,0.21$ and $0.1 \mu M)$. Dissociation data were collected for 120 s. Black lines show the actual data; the orange lines are curve fits. (c) A structural model of the dimer interface of vPIP. Residues in the dimer interface are presented as stick models. In the upper and lower panels each residue in chain A (His58, Glu61, Arg65, Lys162, Glu172, Lys244, Arg254, Asp265 and Glu266) and in chain $B$ (His58, Glu61, Arg65, Lys162, Arg72, Glu172, Lys244, Arg254, Asp265 and Glu266) involved in hydrogen bonds and salt bridges is indicated. The interaction of residues was calculated using PISA. (d) Multi-angle light-scattering and refractive-index curves for vPIP dimerization. Light scattering (LS) is shown in blue and the differential refractive index (dRI) is shown in red. The buffer was removed and the LS and refractive index were measured and plotted against the protein sample. (e) GFP-tagged vPIP and FLAG-tagged vPIP were transfected into HEK293T cells for $48 \mathrm{~h}$. The cells were harvested and subjected to co-IP assays using anti-FLAG. The results were analyzed by Western blotting. 
(Qiagen, Venlo, Netherlands). Real-time PCR with SYBR Green was run at $95^{\circ} \mathrm{C}$ for $15 \mathrm{~min}$, followed by 45 cycles of $95^{\circ} \mathrm{C}$ for $10 \mathrm{~s}, 55^{\circ} \mathrm{C}$ for $15 \mathrm{~s}$ and $72^{\circ} \mathrm{C}$ for $20 \mathrm{~s}$.

\subsection{Western blot analysis}

The whole-cell lysates were resolved by SDS-PAGE, transferred to a polyvinylidene fluoride membrane and probed with primary antibodies against FLAG-M2 (1:2000; Sigma), MYC (1:2000; made in our laboratory), ORF45 (1:500; made in our laboratory), GFP (1:500; Santa Cruz Biotechnology), PARP-1 (1:1000, BD Biosciences) or $\alpha$-tubulin (1:2000; Sigma). A goat anti-rabbit or goat anti-mouse immunoglobulin $\mathrm{G}$ antibody conjugated with horseradish peroxide (a secondary antibody; Santa Cruz Biotechnology) was detected using ECL plus Western blotting detection reagents (ELPIS), and the signals were analyzed on LAS4000, a chemiluminescent image analyzer (Fujifilm).

\subsection{Immunoprecipitation (IP) assays}

After $48 \mathrm{~h}$ of transfection, HEK293T cells were harvested with IP buffer consisting of $20 \mathrm{~m} M$ HEPES $\mathrm{pH}$ 7.4, $100 \mathrm{mM}$ $\mathrm{NaCl}, 0.5 \%$ Nonidet $\mathrm{P}-40,1 \%$ Triton X-100 supplemented with a $1 \%$ volume of a protease-inhibitor cocktail (Sigma). The cell lysates were rotated at $4^{\circ} \mathrm{C}$ for $1 \mathrm{~h}$ and cell debris was removed by centrifugation $\left(14000 \mathrm{~g}, 4^{\circ} \mathrm{C}, 10 \mathrm{~min}\right)$. An antiFLAG antibody (M2, Sigma) was added and the lysates were incubated at $4{ }^{\circ} \mathrm{C}$ with rotation. $30 \mu \mathrm{l}$ of Protein A/G Agarose beads (Pierce) were then added and incubation was continued for $16 \mathrm{~h}$ at $4^{\circ} \mathrm{C}$. The beads were washed with IP buffer and the proteins were analyzed by Western blotting.

\subsection{Immunofluorescence assays (IFAs) and confocal microscopy}

After $24 \mathrm{~h}$, the transfected HEK293T or HeLa cells were fixed for 15 min with $4 \%$ paraformaldehyde and $0.15 \%$ picric acid in PBS. The blocking step was performed with $10 \%$ normal goat serum in PBS containing $0.3 \%$ Triton X-100 and $0.1 \%$ BSA. The anti-PARP-1 antibody (Cell Signaling Technology) was incubated with the cells as a primary antibody for $16 \mathrm{~h}$ at $4^{\circ} \mathrm{C}$. A rabbit anti-Rho antibody (Jackson ImmunoResearch) was incubated with the cells as a secondary antibody for $45 \mathrm{~min}$ at room temperature. 4',6-Diamidino-2phenylindole (DAPI; 1:1,000) was used for nucleus staining for $3 \mathrm{~min}$ at room temperature. The fluorescent images were captured at a magnification of $1000 \times$ using a confocal laser scanning microscope (LSM 5 Exciter, Zeiss).

\subsection{Mouse experiments}

All animal experiments were approved by the Korea University Institutional Animal Care and Use Committee (KUIACUC-2016-119) in accordance with institutional guidelines. Six-week-old BALB/c mice (Samtako) were intranasally infected with WT, vPIP-ST, vPIP mI or vPIP mIMR virus (1000 PFU per mouse, $n=5$ in each group) under anesthesia. The mice were euthanized $6 \mathrm{~d}$ post-infection during acute infection and 17-18 d post-infection during latent infection. For acute-infection analysis, the lung tissues were homogenized in $1 \mathrm{ml}$ DMEM and the virus titers were determined by plaque assays. The viral genome loads in the lung tissues were measured by quantitative real-time PCR. For quantification of latent viral loads, ex vivo limiting-dilution assays and infectious-center assays were performed on Vero cells as described elsewhere (Lee et al., 2007; Noh et al., 2012).

\section{Results}

\subsection{Overall characterization of VPIP}

We determined the structure of full-length MHV-68 ORF49 (PDB entry $6 \mathrm{a} 4 \mathrm{v}$; later called vPIP) at $2.2 \AA$ resolution (Fig. 1a). The structure consists of $12 \alpha$-helices and characteristic $\mathrm{N}$-terminal $\beta$-strands $(\mathrm{N} \beta)$ and forms a Vshaped-twist dimer in the asymmetric unit. Three regions, L1 (amino-acid residues 175-176), L2 (amino-acid residues 231237) and Ct1 (amino-acid residues 280-301), were not visible in the electron-density map of the crystal, suggesting that these regions have high flexibility. In our previous report, MHV-68 ORF49 was shown to interact with PARP-1 in a cellular environment (Noh et al., 2012). The results of surface plasmon resonance (SPR) analysis of the purified ORF49 protein regarding PARP-1 binding affinity in vitro indicated that $K_{\mathrm{d}}$ is approximately $930 \mathrm{n} M$ : sufficient affinity for PARP1 (Fig. 1b). This result clearly revealed the direct physical interaction of ORF49 and PARP-1; therefore, we propose calling MHV-68 ORF49 a viral PARP-1-interacting protein (vPIP). The structure of vPIP was found to have a dimer in the asymmetric unit, and its interface is formed by hydrogen bonds and salt bridges (Fig. 1c). The salt bridges are Arg65 $A^{-}$ Glu266 $6_{B}$ and Lys162 ${ }_{A}-\mathrm{Asp} 265_{B}$ (the protomer is shown as a subscript). Size-exclusion chromatography with multi-angle light scattering (SEC-MALS) verified vPIP dimerization in vitro because the molecular weight (MW) was found to be approximately $76 \mathrm{kDa}$ : double the molecular weight of the vPIP monomer ( $38 \mathrm{kDa}$; Fig. 1d). Co-immunoprecipitation (co-IP) with an anti-FLAG antibody confirmed the dimerization of vPIP in HEK293T cells co-transfected with FLAGtagged vPIP and GFP-fused vPIP (Fig. 1e). These results indicate that vPIP exists as a dimer both in solution and in the cell.

\subsection{Mutagenesis and subcellular localization of vPIP mutants}

On the basis of the structural information on vPIP, we constructed two deletion mutants: vPIP $\Delta \mathrm{N}$ (deletion of amino acids 2-26) lacking the N-terminal $\beta 1$ and $\alpha 1$, and vPIP $\Delta \mathrm{C}$ (deletion of amino acids 277-301) lacking the C-terminal Ct1. In addition, two point mutants, vPIP $\mathrm{mI}$ (F5A, S12A and T16A) and vPIP mP (H47A and D50A), were constructed to understand the functional importance of some vPIP regions. Three residues (Phe5, Ser12 and Thr16), which were found on the surface of vPIP and are likely to participate in interactions with other proteins, were substituted by alanines to create vPIP $\mathrm{mI}$ (an interacting-site mutant), whereas two residues (His47 and Asp50) at the center of the dimer that form a 


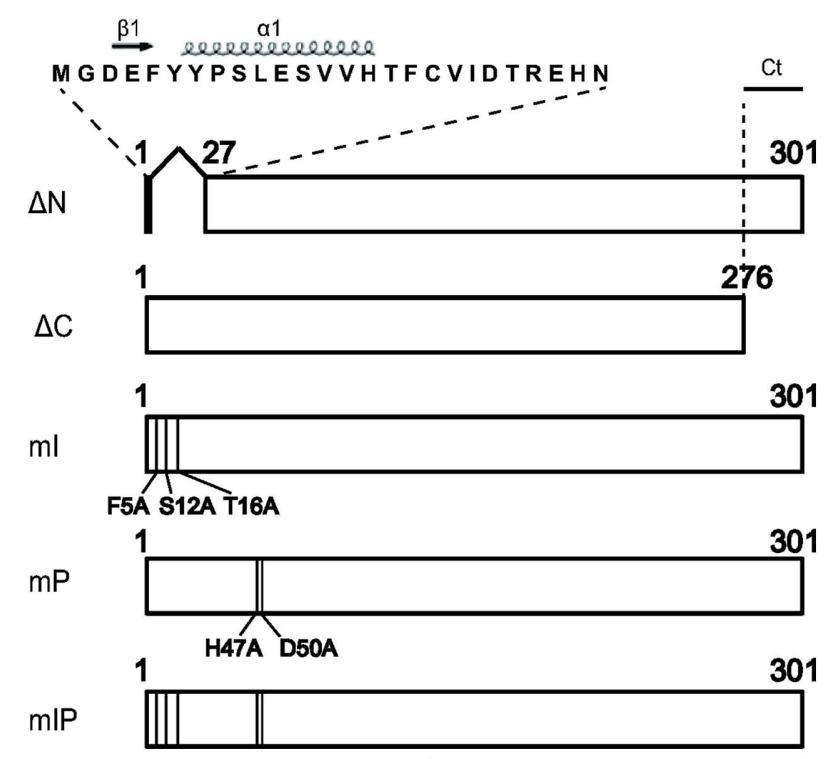

(a)

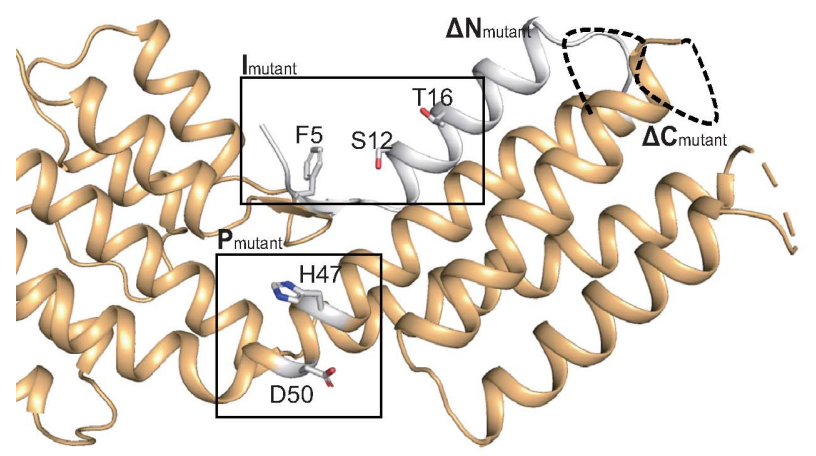

(b)

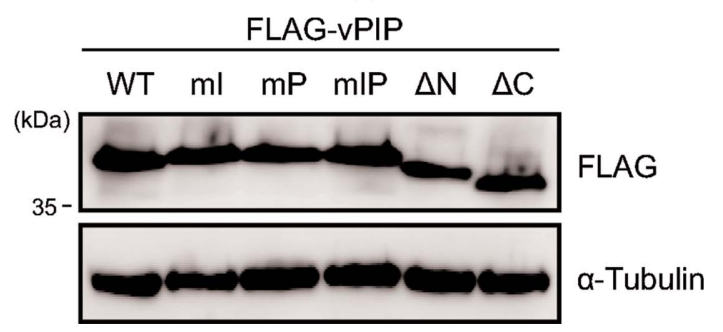

(c)
HeLa
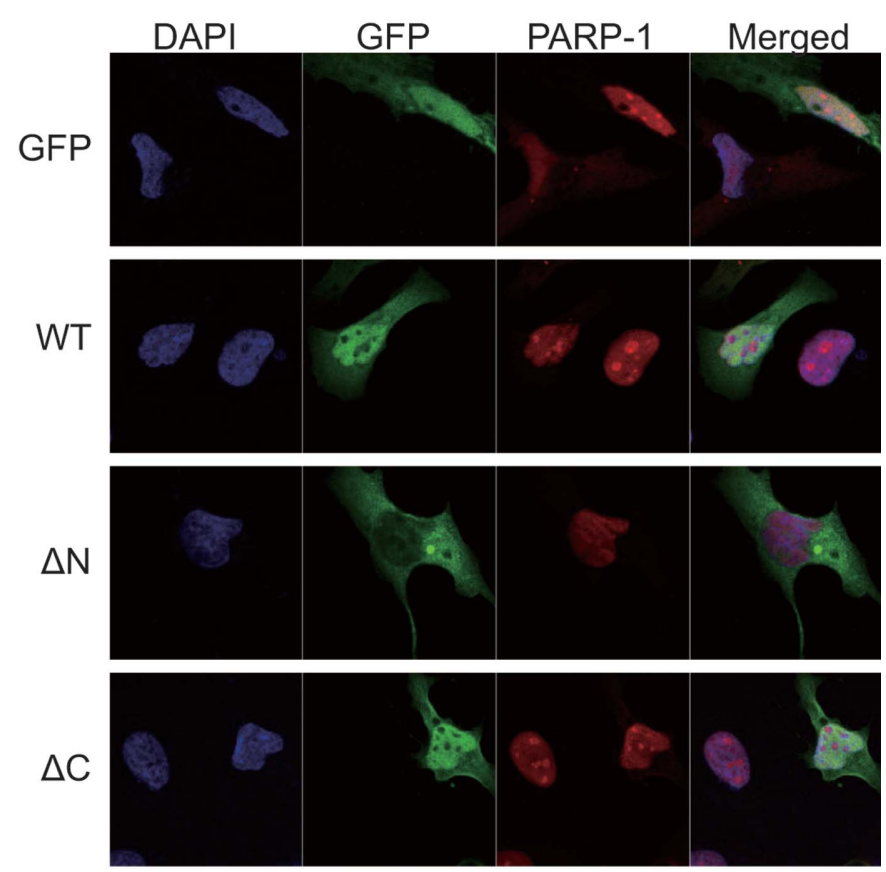

$\mathrm{ml}$
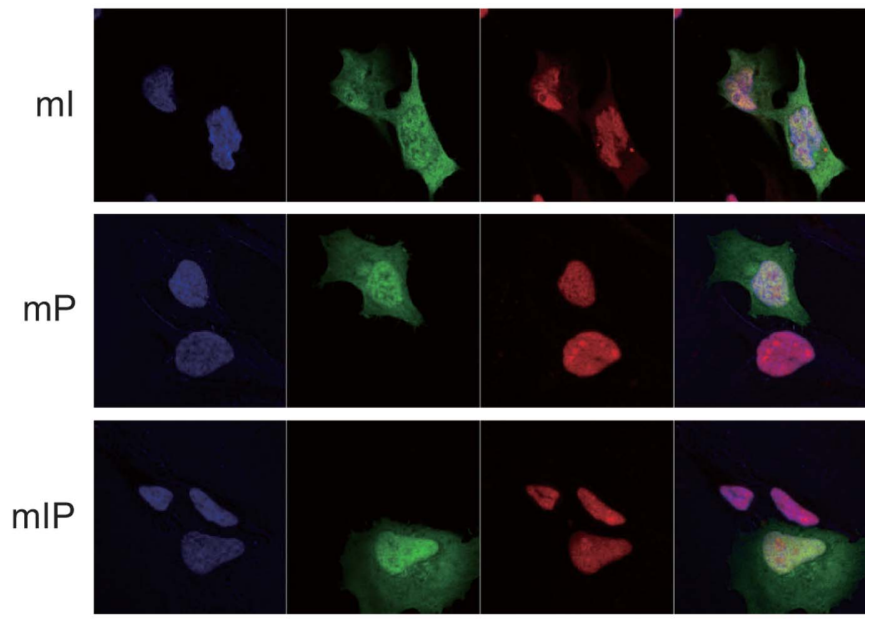

(d)

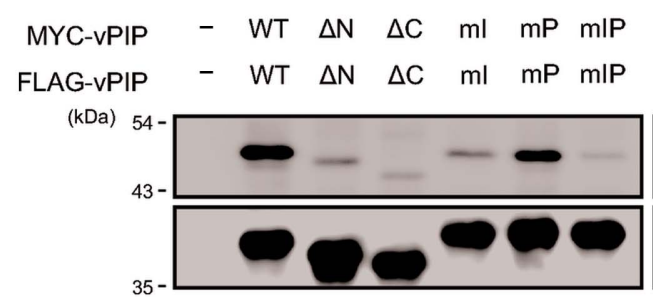

IP: anti-FLAG

Figure 2

$(e)$

- WT $\Delta \mathrm{N} \quad \Delta \mathrm{C} \quad \mathrm{ml} \quad \mathrm{mP} \quad \mathrm{mIP}$

- WT $\quad \Delta \mathrm{N} \quad \Delta \mathrm{C} \quad \mathrm{ml} \quad \mathrm{mP} \quad \mathrm{mlP}$

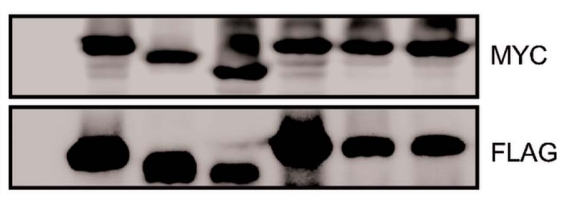

Cell lysates

Construction and characterization of vPIP mutants. (a) Schematic diagram of vPIP deletion and point mutants. Two deletion mutants, vPIP $\triangle \mathrm{N}$ (deletion of amino acids 2-26) for $\mathrm{N} \beta$ and $\alpha 1$ and vPIP $\Delta \mathrm{C}$ (deletion of amino acids 277-301), and two point mutants, vPIP mI (F5A, S12A and T16A) for interaction sites and vPIP $\mathrm{mP}(\mathrm{H} 47 \mathrm{~A}$ and D50A) for pore sites, were constructed. An additional mutant containing both $\mathrm{mI}$ and $\mathrm{mP}$ was also generated (vPIP mIP). (b) The structure of vPIP mutations with positional indicators. The positions of the mutations are marked in the monomer structure of vPIP. (c) Expression of vPIP mutants. FLAG-tagged vPIP mutant constructs were transfected into HeLa cells. After $24 \mathrm{~h}$, expression of the vPIP mutants was analyzed by Western blotting. (d) Subcellular localization of vPIP mutants. HeLa cells were transfected with the GFP-tagged vPIP mutants, fixed at $24 \mathrm{~h}$ post-transfection and immunostained with anti-PARP-1 antibody. The nuclei were stained with DAPI (blue). The scale bar is $20 \mu \mathrm{m}$ in length. (e) Dimerization of vPIP mutants. MYC-tagged vPIP mutants were co-transfected with FLAG-tagged vPIP mutants into HEK293T cells for 48 h. The cells were harvested and subjected to co-IP assays using anti-FLAG. The results were analyzed by Western blotting. 
cavity were substituted by alanines to create vPIP mP (a poresite mutant; Figs. $2 a$ and $2 b$ ). A mutant containing mutations at both the interaction site and the pore site was also generated (vPIP mIP). All of the constructed mutants showed a normal level of expression comparable to that of wild-type (WT) vPIP in transfected cells (Fig. 2c). To examine the subcellular localization of these mutants, GFP-fused mutant constructs were transfected into HeLa cells. Although the WT vPIP protein was expressed in both the cytoplasm and the nucleus, as previously reported (Lee et al., 2007), the vPIP $\Delta \mathrm{N}$ mutant localized only to the cytoplasm; however, the other mutants were expressed both in the nucleus and the cytoplasm (Fig. 2d). The localization patterns of the mutants in HEK293T cells were consistent with the above findings (Supplementary Fig. S1). These results suggest that the $\mathrm{N}$-terminus of vPIP may be essential for nuclear localization of the vPIP protein. When the ability of vPIP mutants to form a dimer was determined in HEK293T cells transfected with
FLAG-tagged and MYC-tagged vPIP mutants in a co-IP experiment, all of the mutants were defective in dimerization except for the pore-site mutant (vPIP mP; Fig. 2e).

\subsection{Effects of vPIP mutations on the regulation of viral lytic} replication

MHV-68 vPIP facilitates viral lytic replication by cooperating with RTA (Lee et al., 2007). To test the functionality of the constructed mutants, we determined whether each vPIP mutant can trans-complement the highly attenuated replication phenotype of a vPIP-deficient virus (Fig. $3 a$ ). The mutant vPIP constructs were co-transfected with BAC DNA harboring the entire genome of MHV-68 (pMHV-68) with triple stop codons in the orf49 (vPIP) gene (vPIP-S; Noh et al., 2012). BAC DNA carrying recombinant virus vPIP-MR, which is free of the triple stop codons of vPIP-S, as well as the wildtype pMHV-68 BAC DNA, served as controls. The results
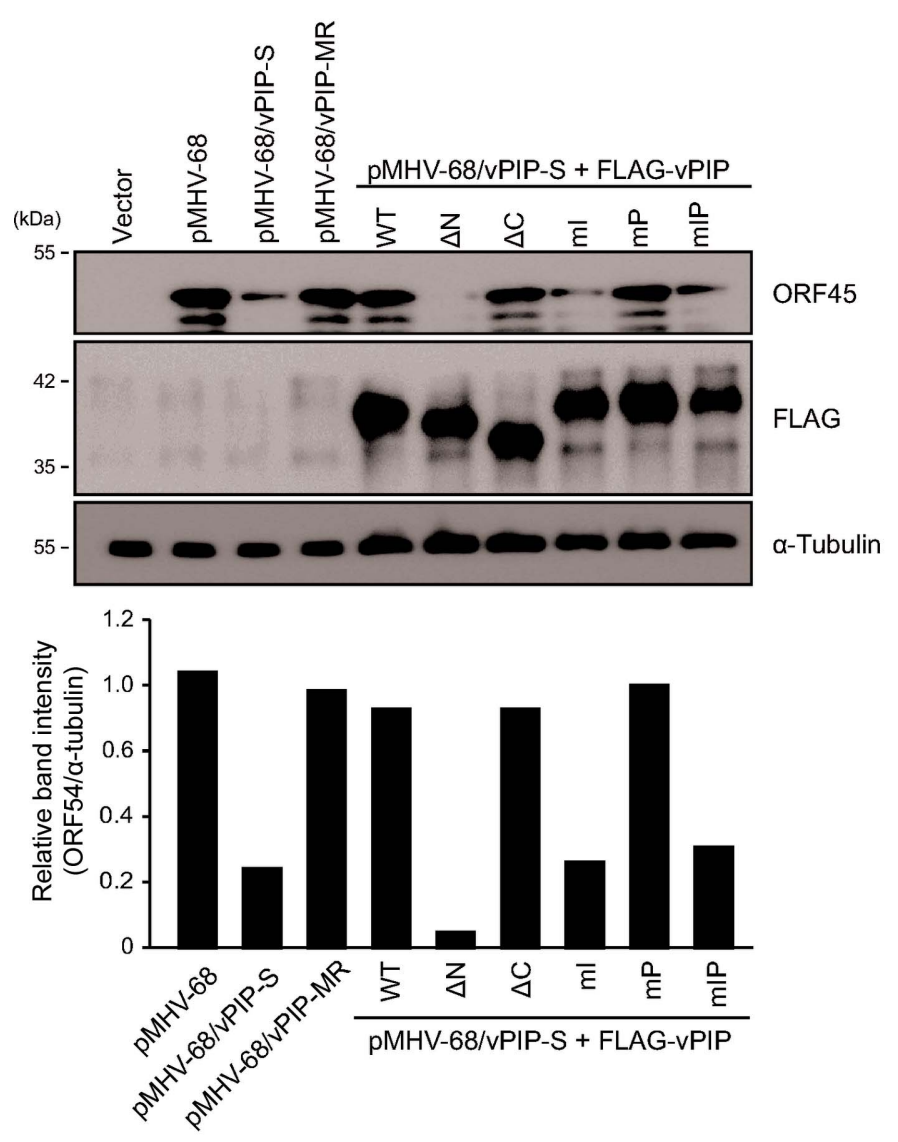

(a)

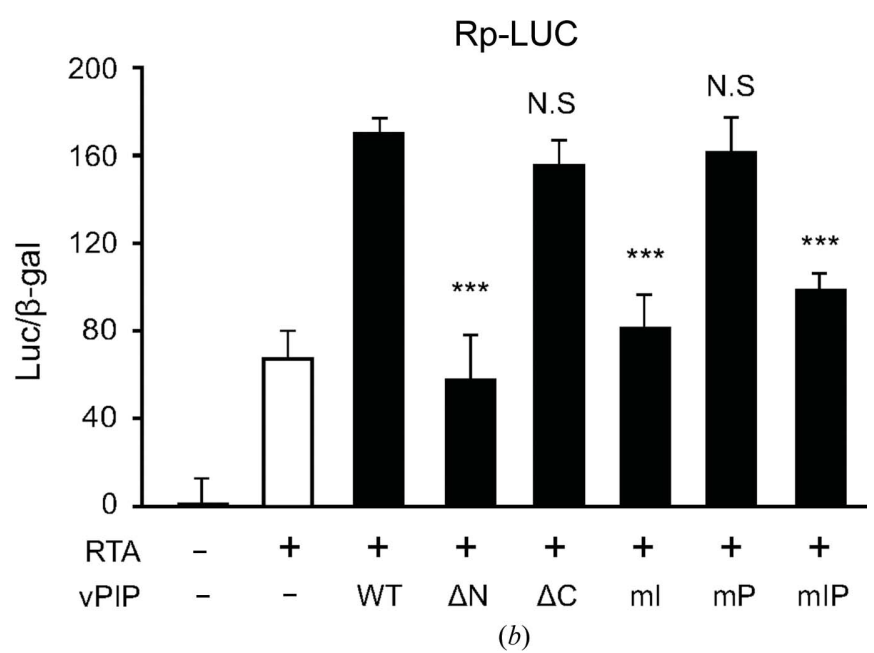

M3p-LUC

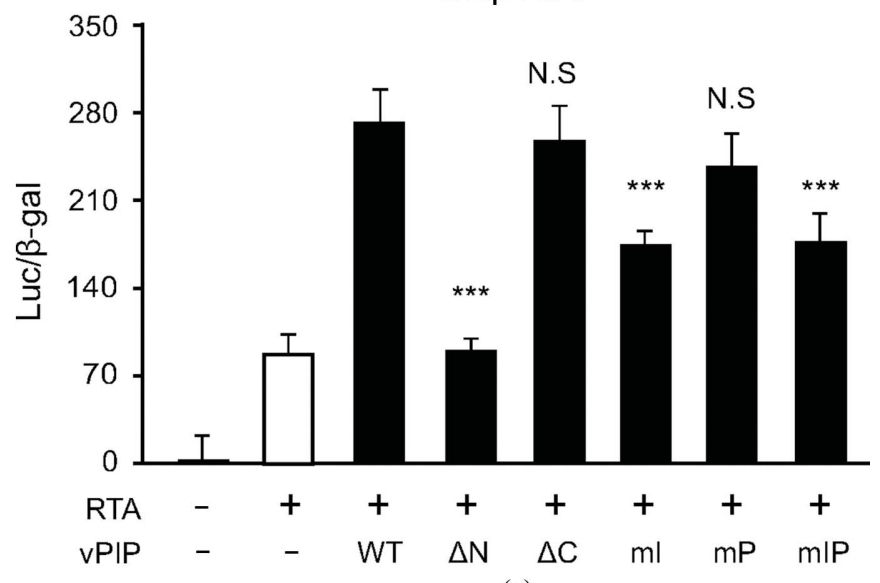

(c)

Figure 3

Effects of vPIP mutations on the regulation of virus lytic replication. (a) Trans-complementation of vPIP-S virus replication by vPIP mutants. Vero cells were co-transfected with FLAG-tagged vPIP mutants in the presence of the vPIP-S virus BAC DNA (pMHV-68/vPIP-S). MHV-68 BAC DNA (pMHV68 ) and vPIP-S-MR were used as a control. After $5 \mathrm{~d}$ of transfection, the cell lysates were subjected to Western blotting. The band intensity of the ORF45 protein was measured and normalized with that of $\alpha$-tubulin using the ImageJ program. $(b, c)$ The effect of vPIP mutants on RTA-mediated transactivation. HEK293T cells were transfected with the reporter construct containing RTA promoter (Rp-LUC) (b) or M3 promoter (M3p-LUC) (c), and vPIP mutants in the presence of RTA-expressing plasmid. Each transfection was performed in triplicate, with a $\beta$-galactosidase-expressing plasmid included as an internal control. Statistical analysis was performed using a two-sided Student's t-test (*** denotes a $P$ value of $<0.005$ against WT vPIP expressing samples). 
showed that the vPIP $\Delta \mathrm{N}$, vPIP $\mathrm{mI}$ and vPIP mIP proteins failed to reverse the attenuation of replication in the vPIP-S virus, whereas vPIP $\Delta \mathrm{C}$ and $\mathrm{vPIP} \mathrm{mP}$ were capable of transcomplementing the replication defect of the vPIP-S virus (Fig. 3a). Because vPIP enhances RTA-mediated transactivation of lytic gene promoters (Lee et al., 2007), we tested whether vPIP mutants retained the ability to increase RTAmediated transactivation in reporter assays with the RTA promoter (Rp-LUC) or RTA-responsive M3 promoter (M3pLUC; Figs. $3 b$ and $3 c$ ). In agreement with other reports (Noh et al., 2012; Lee et al., 2007), RTA alone activated both promoters and WT vPIP enhanced RTA-mediated transactivation (Figs. $3 b$ and $3 c$ ). In contrast, the mutant proteins vPIP $\Delta \mathrm{N}$, vPIP $\mathrm{mI}$ and vPIP mIP were unable to promote RTA-mediated transactivation, whereas vPIP $\Delta \mathrm{C}$ and vPIP
$\mathrm{mP}$ enhanced it to levels similar to those of the WT (Figs. $3 b$ and $3 c$ ). These results indicate that the N-terminus of vPIP is essential for its function, as shown for vPIP $\Delta \mathrm{N}$. Moreover, the $\mathrm{N}$-terminal residues, especially Phe5, Ser12 and Thr16, of vPIP were critical for the enhancement of RTA-mediated transactivation in the nucleus.

\subsection{Molecular interactions of vPIP mutants with PARP-1 and RTA}

As a molecular mechanism for the promotion of viral lytic replication by vPIP, it has been proposed that vPIP interacts with and sequesters PARP-1, thus disrupting the interaction of PARP-1 with RTA and reducing the amount of PARylated RTA (Noh et al., 2012). In addition, vPIP directly binds to

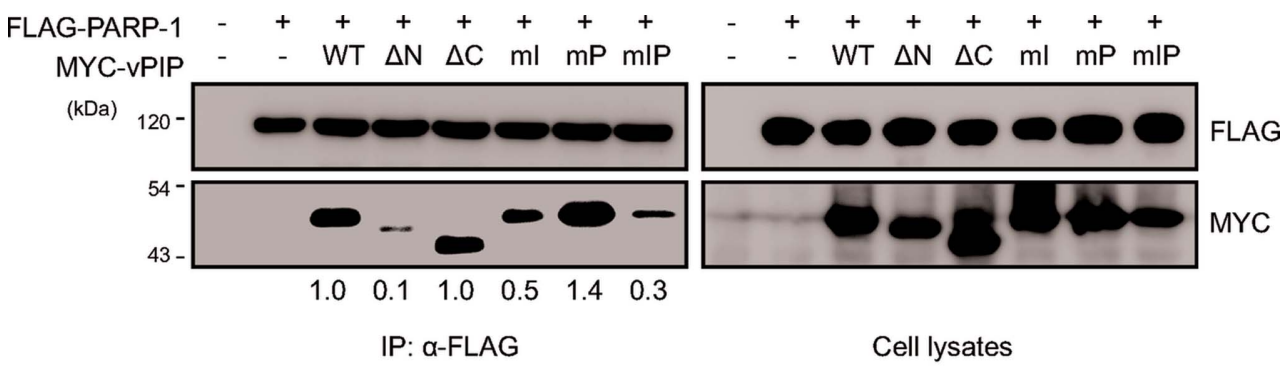

(a)

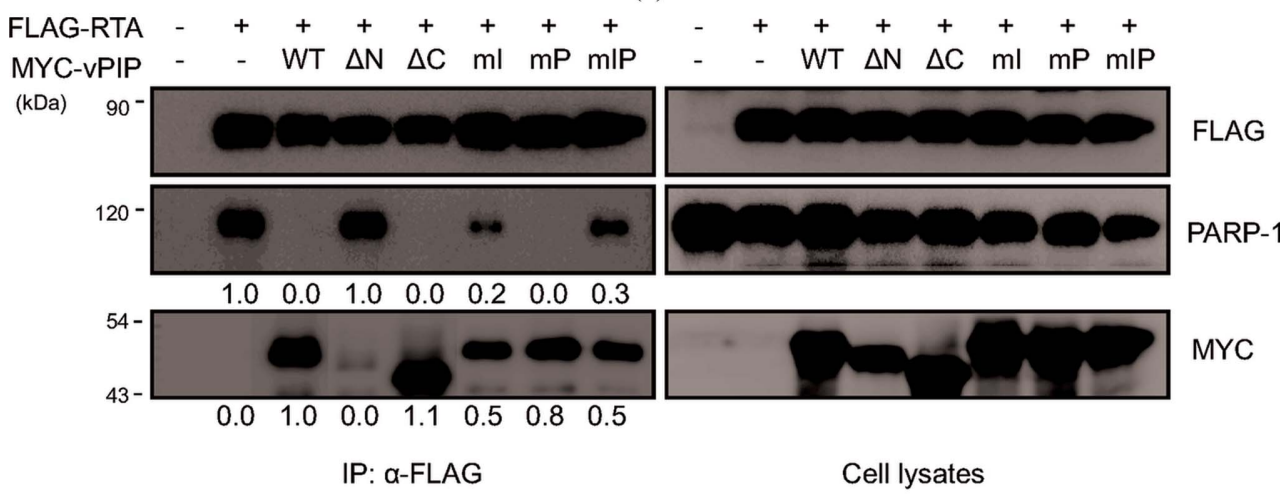

(b)

\begin{tabular}{r|cccccc} 
& $\mathbf{W T}$ & $\mathbf{\Delta N}$ & $\mathbf{\Delta C}$ & $\mathrm{ml}$ & $\mathrm{mP}$ & $\mathrm{mIP}$ \\
\hline \hline Subcellular localization & $\mathrm{N}, \mathrm{C}$ & $\mathrm{C}$ & $\mathrm{N}, \mathrm{C}$ & $\mathrm{N}, \mathrm{C}$ & $\mathrm{N}, \mathrm{C}$ & $\mathrm{N}, \mathrm{C}$ \\
Dimerization & + & - & - & - & + & - \\
PARP-1 interaction & +++ & - & ++ & + & +++ & + \\
RTA interaction & ++ & - & ++ & + & ++ & + \\
PARP-1 interaction with RTA & - & ++ & - & + & - & + \\
RTA transactivation activity & ++ & - & ++ & - & ++ & - \\
Transcomplementation & ++ & - & ++ & - & ++ & -
\end{tabular}

(c)

Figure 4

Molecular interactions of vPIP mutants with PARP-1 or RTA. (a) Interaction between vPIP mutants and PARP-1. MYC-tagged vPIP mutants were co-transfected with FLAG-tagged PARP-1 into HEK293T cells. The cells were harvested $48 \mathrm{~h}$ post-transfection and analyzed by co-IP assays with the anti-FLAG antibody. The results were examined by Western blotting. The band intensity of MYC in IP blots was measured using the ImageJ software. (b) Inhibition of interactions between RTA and PARP-1 by vPIP mutants. MYCtagged vPIP mutants were co-transfected with FLAG-tagged RTA into HEK293T cells. The cells were harvested $48 \mathrm{~h}$ post-transfection and subjected to co-IP assays with the anti-FLAG antibody. The results were examined by Western blotting. The band intensity of PARP-1 and MYC in IP blots was measured in ImageJ. (c) A summary of subcellular localization, protein-protein interactions and functional activities of WT vPIP and mutants.
RTA, suggesting that there may be a direct effect of vPIP on the activity of RTA (Noh et al., 2012). Firstly, we examined the molecular interaction of vPIP mutants with PARP-1 by co-transfecting FLAG-PARP-1 with one of the MYC-vPIP mutants followed by a co-IP experiment (Fig. 4a). Consistent with the functional results on vPIP mutants in transcomplementation and reporter assays, the interactions of the mutant proteins vPIP $\triangle \mathrm{N}$, vPIP $\mathrm{mI}$ and vPIP mIP with PARP-1 were severely impaired or attenuated, but those of the mutant proteins vPIP $\Delta \mathrm{C}$ and vPIP $\mathrm{mP}$ were not affected. Next, we evaluated the effects of these mutations on the interaction of RTA with vPIP as well as that of RTA with PARP-1 (Fig. 4b). Although the interactions of the mutant proteins vPIP $\triangle \mathrm{C}$ and vPIP $\mathrm{mP}$ with RTA showed no significant difference from that of the WT, there were reduced or nonexistent interactions of vPIP $\Delta \mathrm{N}$, vPIP $\mathrm{mI}$ and vPIP mIP with RTA. Moreover, the intensity of the RTA-PARP-1 interaction was affected by the presence of vPIP mutant proteins; the vPIP $\Delta \mathrm{C}$ and vPIP $\mathrm{mP}$ mutants completely disrupted the RTA-PARP-1 interaction, as did the WT, whereas vPIP $\Delta \mathrm{N}$ did not disrupt the RTA-PARP-1 interaction at all, and the vPIP $\mathrm{mI}$ and vPIP mIP mutant proteins were partially impaired in interfering 
with the RTA-PARP-1 interaction (Fig. 4b). To further examine whether the defective function of vPIP $\Delta \mathrm{N}$ is owing to its cytoplasmic localization, an additional mutant construct, vPIP $\Delta \mathrm{N}+\mathrm{NLS}_{\mathrm{SV} 40}$, was generated by inserting a classical nuclear localization signal (NLS) from the SV40 large T-antigen (PKKKRKV; Ng et al., 2018). While the new construct was only expressed in the nucleus, it was still defective in interacting with PARP-1 and RTA like vPIP $\Delta \mathrm{N}$, thereby not being able to alleviate the repression of RTA by PARP-1 (Supplementary Fig. S2). Taken together, these results suggest that the $\mathrm{N}$-terminal residues, especially Phe5, Ser12 and Thr16, of vPIP may be critical for the interaction of vPIP with PARP-1 and RTA, thereby interfering with the interactions between RTA and PARP-1. The molecular phenotypes of vPIP mutants are summarized in Fig. 4(c).

\subsection{Construction and in vitro replication of the mutant virus (vPIP ml)}

To investigate the roles of key residues (Phe5, Ser12 and Thr16) of vPIP in the context of virus replication, the vPIP mI recombinant virus containing alanine substitutions of three residues (F5A, S12A and T16A) was generated by a REDmediated recombination method (Yu et al., 2000; Tischer et al., 2006). A corresponding marker rescue virus (vPIP mI-MR) that was free of these mutations was also constructed as a control (Fig. $5 a$ ). The introduced mutations were confirmed by sequencing (Fig. 5a), and the genome integrity of the recombinant virus clones was verified by restriction-enzyme digestion of the BAC clones (Fig. 5b). In a multiple-step growth analysis of the WT, vPIP-S, vPIP mI and vPIP mI-MR viruses, the replication rates of the vPIP-S and vPIP mI viruses were found to be significantly attenuated when compared with those of the WT or vPIP mI-MR viruses (Fig. 5c). Infection with the vPIP mI or vPIP-S virus resulted in plaques of smaller size relative to the WT and vPIP mI-MR viruses, although the plaques of the vPIP-S virus were even smaller than those of the vPIP mI virus (Figs. $5 d$ and $5 e$ ). These results suggest that the three amino-acid residues at the N-terminus of vPIP that are important for its interaction with PARP-1 and derepression of RTA may be crucial for viral replication in vitro.

\subsection{Acute infection and in vivo latency of the mutant virus (vPIP ml)}

To determine the effect of vPIP mutations on MHV-68 infection in vivo, we intranasally infected $\mathrm{BALB} / \mathrm{c}$ mice with WT, vPIP-S, vPIP mI or vPIP mI-MR virus (1000 plaqueforming units per mouse). Lung tissues were collected at $6 \mathrm{~d}$ post-infection during acute infection. Compared with that of the WT or vPIP mI-MR viruses, lytic replication of the vPIP $\mathrm{mI}$ virus was highly attenuated (as much as the vPIP-S virus) in the lungs during acute infection (Figs. $6 a$ and $6 b$ ). To further evaluate the latent infection in mice after intranasal inoculation, the spleen was harvested 17-18 d post-infection (Figs. $6 c$ and $6 f$ ). Mice infected with vPIP mI or vPIP-S viruses had a smaller spleen in comparison with mice infected with WT or vPIP mI-MR viruses (Fig. 6c). Just as in vPIP-S virus infection,
vPIP mI virus infection showed attenuated viral latency in splenocytes as revealed by infectious-center assays and limiting-dilution assays (Figs. $6 d$ and $6 e$ ). The viral genome loads in the splenocytes were lower in the mice infected with the vPIP $\mathrm{mI}$ or vPIP-S viruses than in mice infected with the WT or vPIP mI-MR viruses (Fig. $6 f$ ). Taken together, these data suggest that the three N-terminal residues of vPIP (Phe5, Ser12 and Thr16) may be important for viral infection in vivo as well as for in vitro lytic replication.

\subsection{The conserved mechanism of action of gammaherpesvirus orf49-encoded proteins}

$\mathrm{KSHV}$, an oncogenic human gammaherpesvirus, also

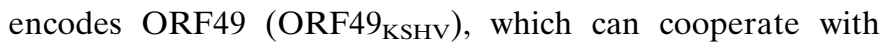
RTA to activate lytic promoters (González et al., 2006). We set out to determine whether gammaherpesvirus ORF49 homologs may share mechanisms of action (Fig. 7). Molecular interactions of ORF49 ${ }_{\mathrm{KSHV}}$ with PARP-1 were found in co-IP assays (Fig. $7 a$ ). The SPR results indicated that ORF49 $9_{\mathrm{KSHV}}$ directly bound to PARP-1 with a $K_{\mathrm{d}}$ of $410 \mathrm{n} M$ (Fig. $7 b$ ). Moreover, reciprocal co-IP data showed that ORF49 $9_{\mathrm{KSHV}}$ interacted with PARP-1 and abrogated the interaction between KSHV RTA and PARP-1 (Figs. $7 c$ and $7 d$ ), suggesting that ORF49 ${ }_{\mathrm{KSHV}}$ may share a conserved mechanism of action with MHV-68 vPIP in terms of derepressing RTA by sequestering PARP-1. In contrast to vPIP, however, a direct interaction of ORF49 $9_{\mathrm{KSHV}}$ and RTA was not detected (Fig. 7c). In addition, the results of SEC-MALS using purified ORF49 $9_{\mathrm{KSHV}}$ and co-IP assays suggested that ORF49 ${ }_{\mathrm{KSHV}}$ exists as a monomer in solution and in the cellular environment (Supplementary Fig. S4). Like vPIP, we also tested whether the functional importance of the N-terminus is conserved in ORF49 ${ }_{\mathrm{KSHV}}$. Alignment of the N-terminal regions of vPIP and ORF49 ${ }_{\mathrm{KSHV}}$ revealed limited homology between these proteins, with an extra 13 amino acids at the beginning of ORF49 ${ }_{\mathrm{KSHV}}$. However, they share the conserved structure of a short $\beta$-strand and an $\alpha$-helix at the $\mathrm{N}$-terminus. We constructed ORF49 ${ }_{\text {KSHV }} \Delta \mathrm{N}$ (deletion of amino acids 236) lacking the $\mathrm{N}$-terminal residues in a similar position to vPIP $\Delta \mathrm{N}$ (Supplementary Fig. S5a). ORF49 KSHV $_{\text {and }}$ ORF49 ${ }_{\text {KSHV }} \Delta \mathrm{N}$ were detected both in the nucleus and the cytoplasm (Supplementary Fig. S5b). However, unlike wildtype ORF49 ${ }_{\mathrm{KSHV}}$, the ORF49 ${ }_{\mathrm{KSHV}} \Delta \mathrm{N}$ mutant failed to interact with PARP-1 (Fig. 7e). These results suggest that the functional importance of the $\mathrm{N}$-terminus is conserved in both MHV-68 and KSHV gamma-2 herpesviruses. Despite the difference in dimerization and in interaction with RTA, our results clearly indicate that the ability of ORF49 homologs to interact with PARP-1 and interfere with the interactions between PARP-1 and RTA is highly conserved between these two oncogenic gamma-2 herpesviruses.

\section{Discussion}

PARP-1, an abundant nuclear protein, participates in multiple cellular activities and is known to inhibit oncogenic 

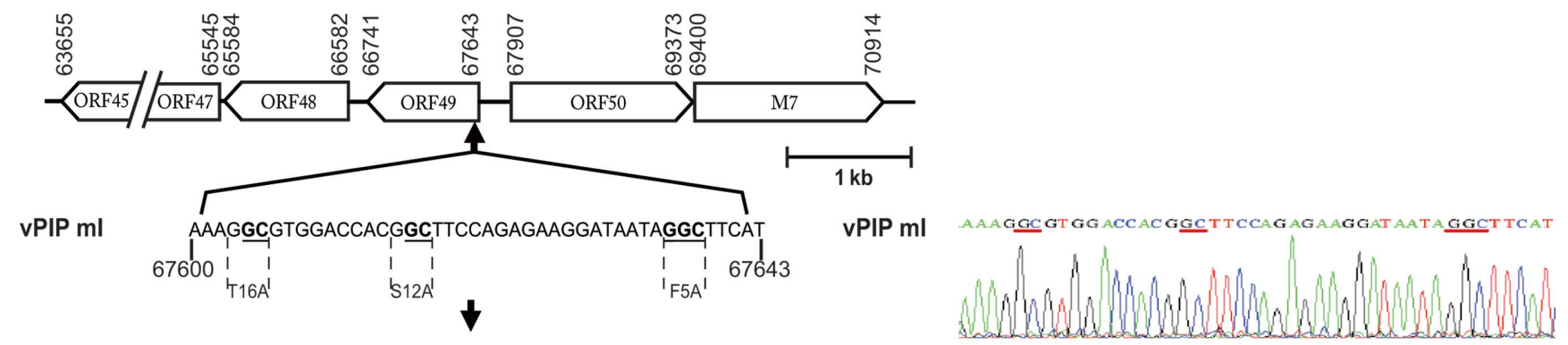

vPIP ml-MR

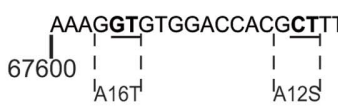

A12S

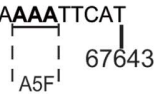

(a)
VPIP MI-MR AAAGGTGTGGAC CAC GCTTTCCAGAGAAGGATAAT AAAAT TCAT

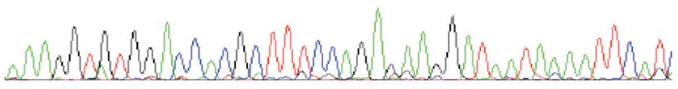

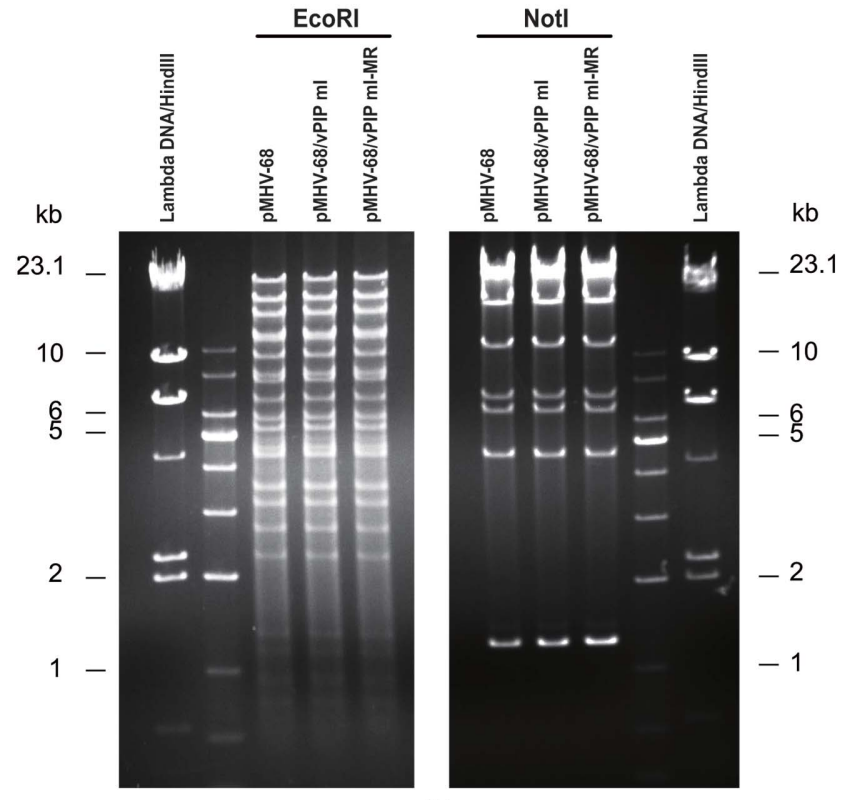

(b)

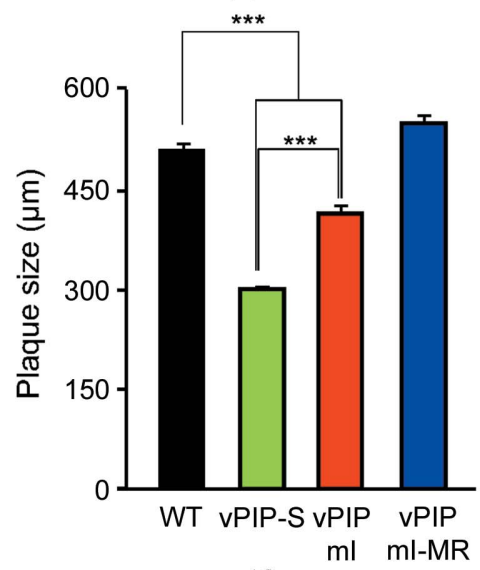

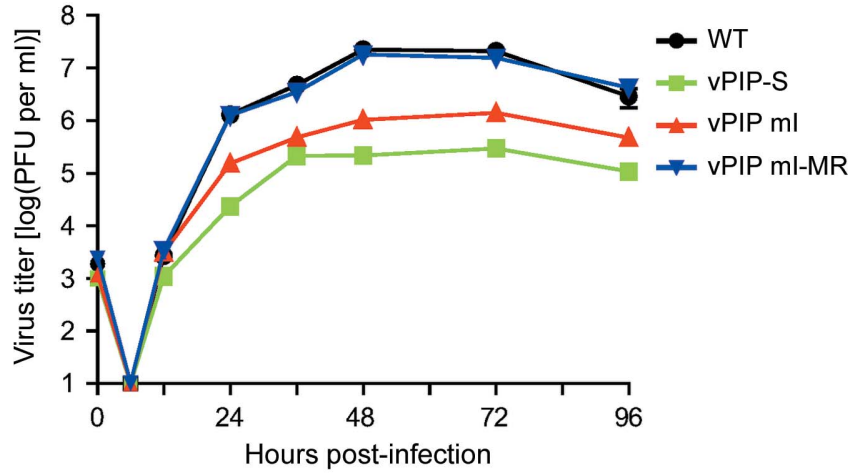

(c)

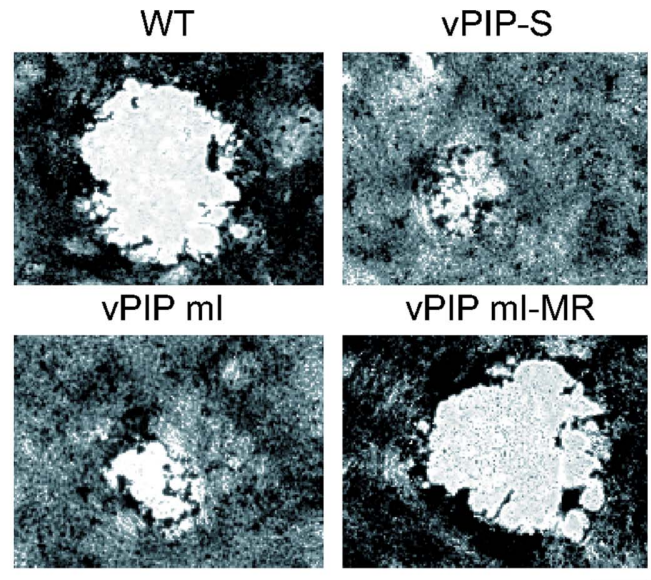

(e)

Figure 5

$(d)$

Creation and in vitro replication of the mutant virus (vPIP mI). (a) A schematic diagram of the ORF49 gene locus in the MHV-68 genome. Open reading frames are shown as boxes. The arrowheads of the boxes indicate the direction of transcription. The numbers indicate the positions of each part within the viral genome. The recombinant viruses vPIP $\mathrm{mI}$ and vPIP mI-MR were constructed as indicated and the mutated positions in the recombinant viruses were confirmed by sequencing. (b) The genome integrity of the recombinant virus BAC clones was verified by digestion with the EcoRI or NotI restriction enzyme. (c) Multiple-step replication curves of the WT, vPIP-S, vPIP mI and vPIP mI-MR viruses. BHK21 cells were infected with the WT, vPIP-S, vPIP mI or vPIP mI-MR virus in triplicate at a multiplicity of infection (MOI) of 0.05 and were harvested at the indicated time points. The virus titers in the cells and the supernatants were analyzed by plaque assays. $(d, e)$ Plaque sizes of the WT, vPIP-S, vPIP mI and vPIP mI-MR viruses. Plaque assays were performed on Vero cells and the diameters of the plaques were determined for at least 100 plaques per virus. The average plaque sizes are shown with the standard error in $(d)$. Statistical analysis was performed by a two-sided Student's t-test (*** denotes $P<0.005$ ). Representative pictures of actual plaques are shown in (e). The scale bar is $200 \mu \mathrm{m}$ in length. 
gammaherpesvirus lytic replication by PARylating RTA, a key switch molecule in lytic replication, thus downregulating lytic genes (González et al., 2006). ORF49 homologs are encoded by all gammaherpesviruses, and cooperate with RTA and positively regulate viral replication (González et al., 2006; Hong et al., 2004; Lee et al., 2007). According to previous studies, MHV-68 ORF49 promotes viral lytic replication via interactions with PARP-1 and RTA by relieving the inhibitory effect of PARP-1 on RTA (Lee et al., 2007; Noh et al., 2012). Here, we present a structure-based molecular mechanism for a viral strategy using MHV-68 ORF49 to overcome PARP-1 inhibition during viral replication. MHV-68 ORF49 directly interacted with PARP-1 in solution without any other cellular factors; this action was found to be conserved in ORF49 ${ }_{\mathrm{KSHV}}$, thereby prompting us to propose a new name for MHV-68 ORF49: viral PARP-1-interacting protein (vPIP). The $\mathrm{N}$ terminal $\beta$-strand region $(\mathrm{N} \beta)$ and $\alpha 1$ helix (amino-acid residues 2-26) turned out to be critical for the nuclear localization, PARP-1 interaction and molecular function of vPIP (Figs. 2, 3 and 4). Three residues at the N-terminus (Phe5, Ser12 and Thr16) were crucial for its PARP-1 interaction and molecular function. Furthermore, a recombinant virus harboring alanine substitutions of these three residues showed severely attenuated viral replication both in vitro and in vivo, suggesting that the interaction of vPIP with PARP-1 is essential for the ability to facilitate viral replication.

In this study, direct interaction of vPIP with PARP-1 was confirmed in vitro in SPR assays, in addition to in vivo in co-IP

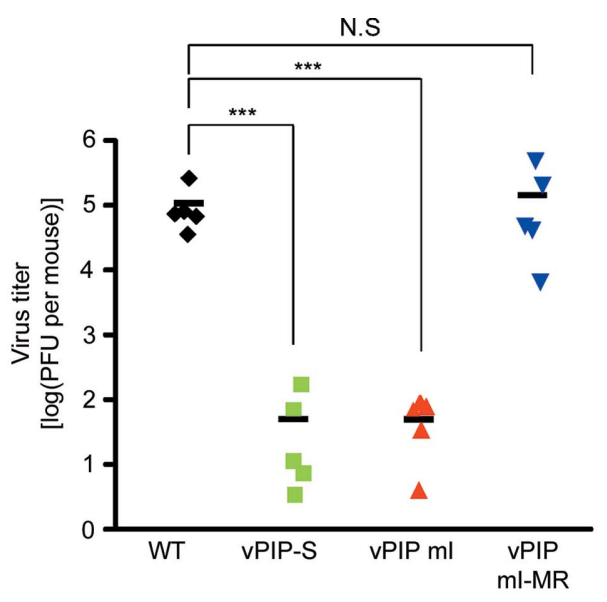

(a)

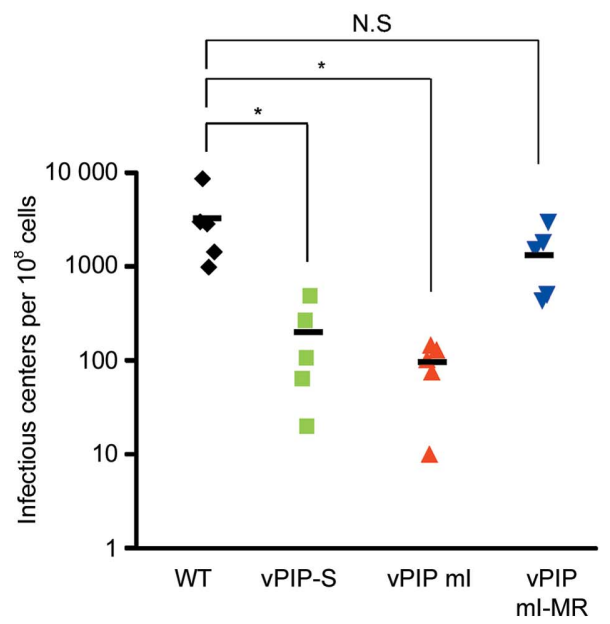

$(d)$

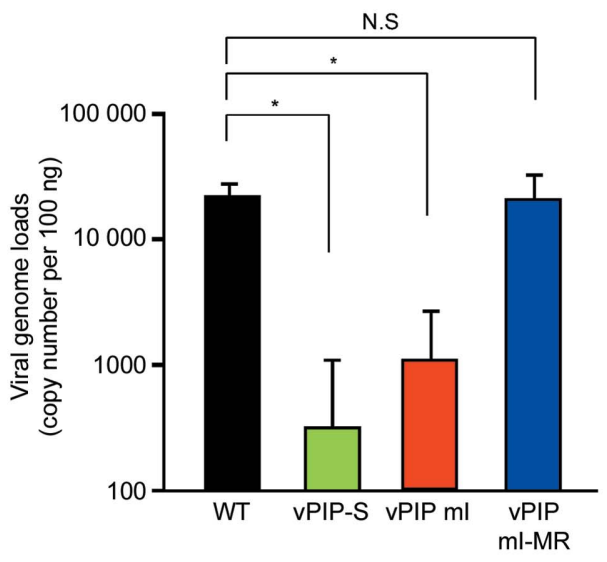

(b)

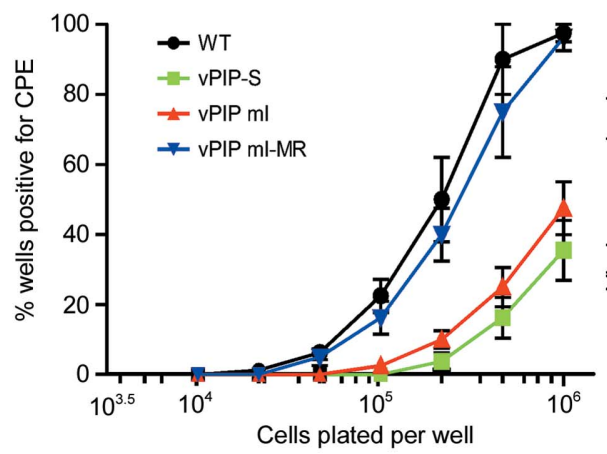

(e)

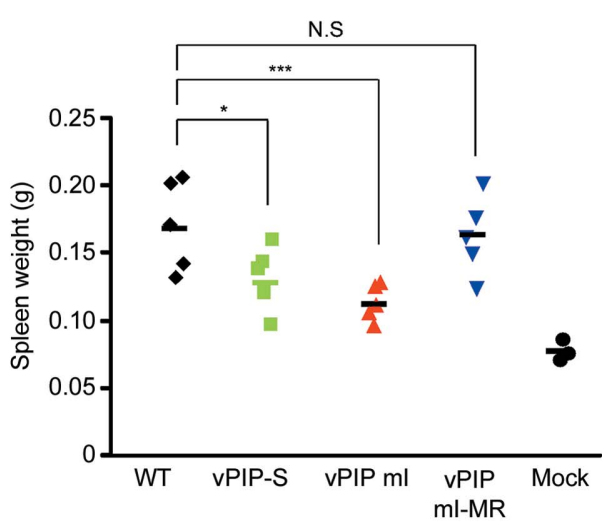

(c)

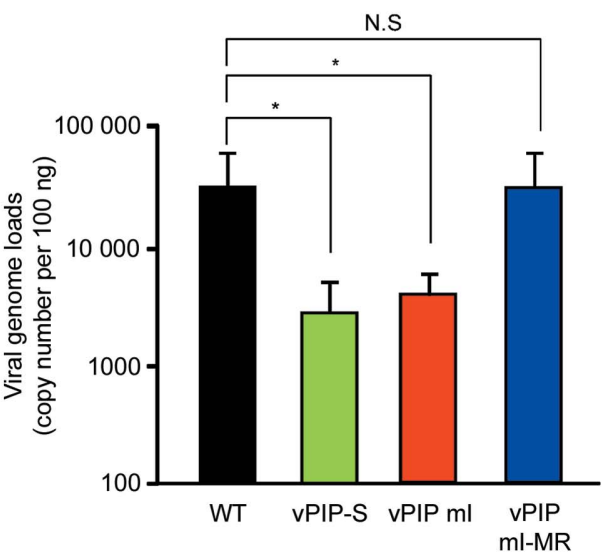

$(f)$

In vivo acute and latent infections by the mutant virus (vPIP $\mathrm{mI}$ ). BALB/c mice were intranasally infected with 1000 plaque-forming units of WT, vPIP-S, vPIP mI or vPIP mI-MR virus. $(a, b)$ Acute infection with the vPIP mI mutant in the lungs. At 6 d post-infection the lungs were excised and homogenized to determine lytic viral titers in plaque assays $(a)$. Each symbol represents the viral titer from the lung tissue of individual mice, with the bar showing the mean value ( $n=5$ in each group). The genomic DNA samples were extracted from the lungs of infected mice. The viral genome copy numbers were quantitated by real-time PCR $(b)$. The average viral genome copy numbers are shown with the standard error of the mean. $(c-f)$ Latent infection with the mutant (vPIP mI) in the spleen. At 17-18 d post-infection, the spleens were excised and their weights were measured (c). The splenocytes were prepared and examined for the frequency of cells reactivating the virus by ex vivo infectious-center assays $(d)$ and a limiting-dilution assay $(e)$. In the limiting-dilution assay, each symbol represents the average percentage of wells positive for cytopathic effects with the standard error of the mean $(n=5$ in each group). In infectious-center assays, each symbol represents the viral titer from individual mice, with the bar showing the mean value. The genomic DNA samples were extracted from splenocytes of the infected mice. The viral genome copy numbers were quantitated by real-time PCR $(f)$. The average viral genome copy numbers are shown with standard errors of the mean ( $n=5$ in each group). Statistical analysis was performed by a two-sided Student's t-test (* denotes $P<0.05$ and *** denotes $P<0.005$ ). 
assays (Fig. 1). Together with the previous study (Noh et al., 2012), our results clearly identified PARP-1 as a genuine interaction partner and target of vPIP. ORF49 ${ }_{\mathrm{KSHV}}$ also strongly interacted with PARP-1 as shown in in vivo and in vitro assays (Fig. 7). Although interaction with RTA was not observed, ORF49 $9_{\text {KSHV }}$ also exerted action on PARP-1, and this interaction abrogated the interaction of RTA and PARP-1. Therefore, these results suggest that the interaction of orf49-encoded proteins with PARP-1 is conserved among gammaherpesviruses and is important for the function of these proteins in viral lytic replication.

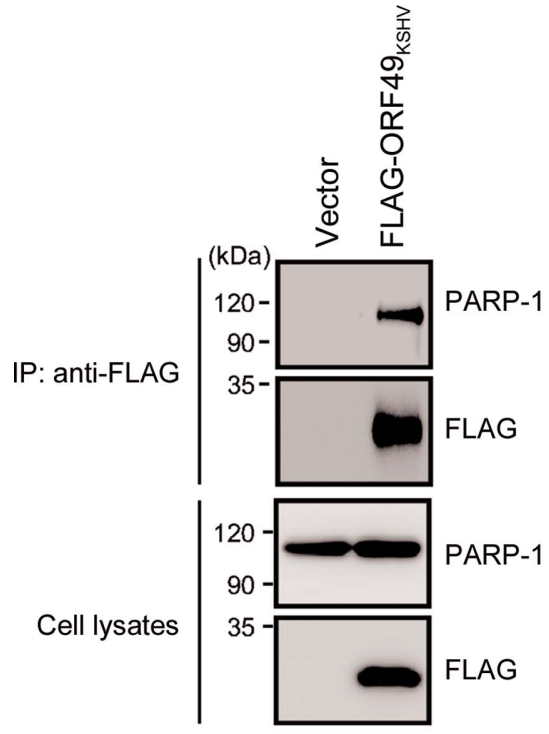

(a)

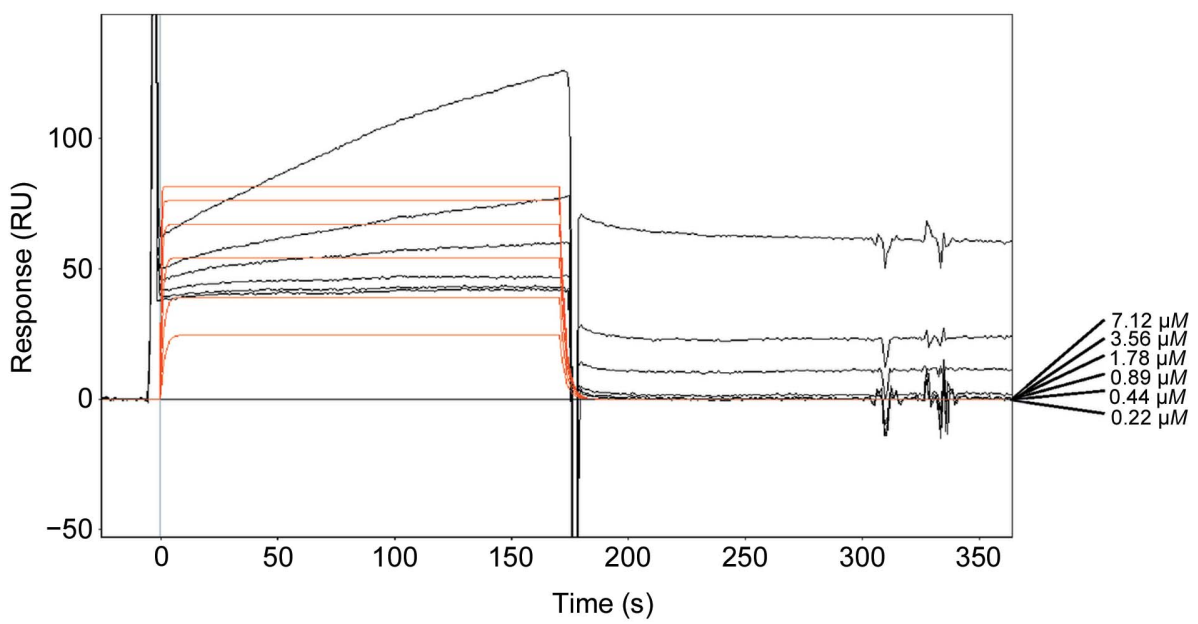

(b)

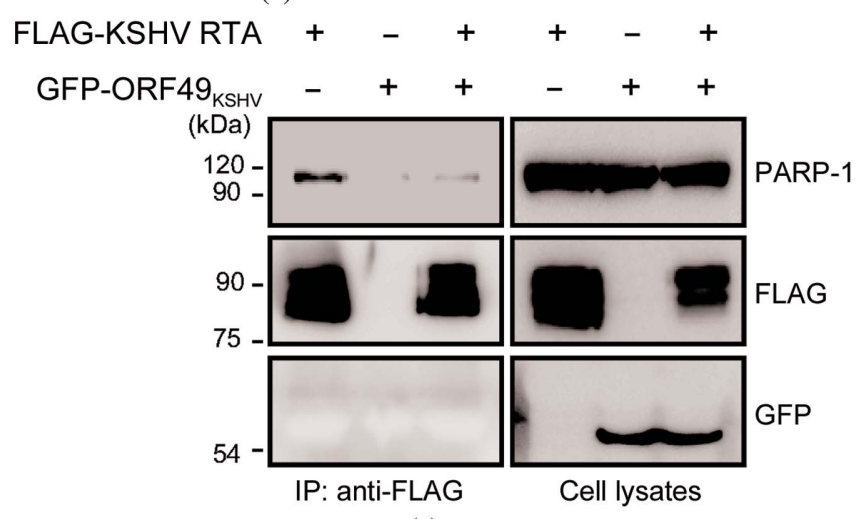

(c)

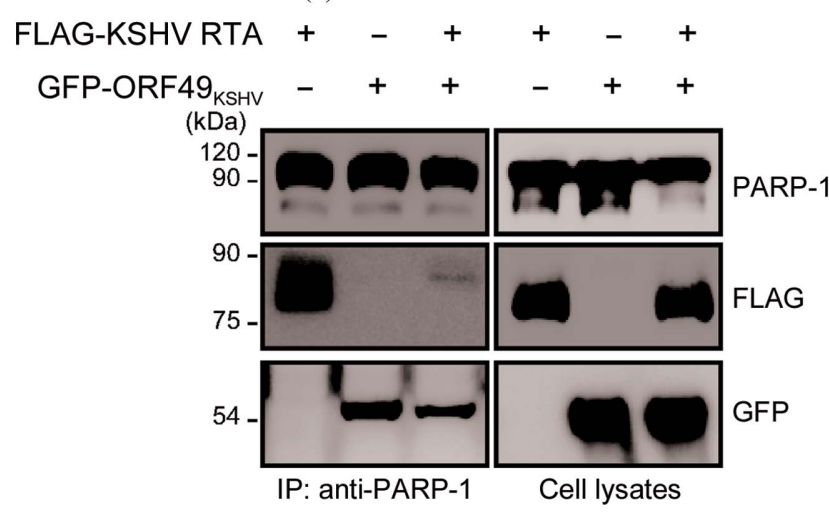

(d)

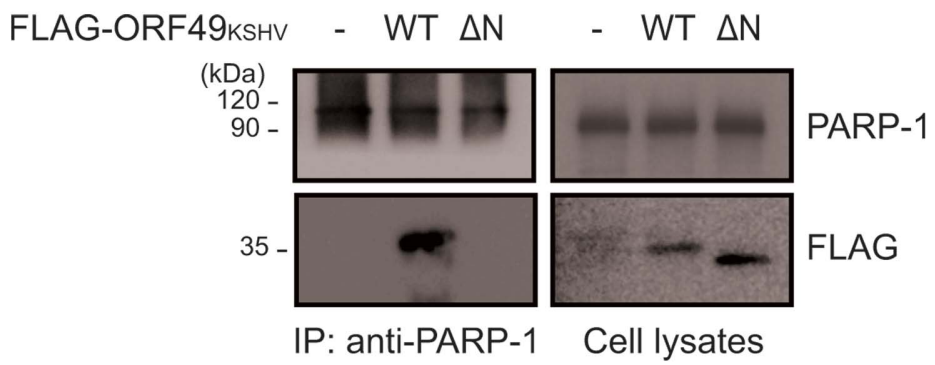

(e)

Figure 7

The conserved molecular mechanism of ORF49 ${ }_{\mathrm{KSHV}}$ interacting with PARP-1. (a) Interaction with PARP-1. FLAG-tagged ORF49 KSHV $_{\text {was transfected }}$ into HEK293T cells and incubated for $48 \mathrm{~h}$. The cells were harvested and analyzed by co-IP assays with an anti-FLAG antibody. (b) SPR analysis of

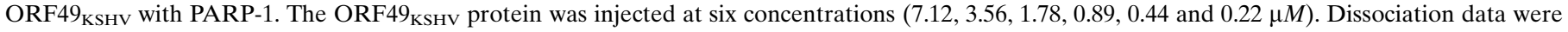
collected for $120 \mathrm{~s}$. The black lines show the actual data; the orange lines are curve fits. $(c, d)$ Inhibition of interactions between RTA and PARP- 1 by ORF49 ${ }_{\text {KSHV }}$ GFP-tagged ORF49 KSHV $_{\text {was }}$ co-transfected with FLAG-tagged RTA into HEK293T cells. The cells were harvested $48 \mathrm{~h}$ post-transfection and subjected to co-IP assays with an anti-FLAG antibody $(c)$ or an anti-PARP-1 antibody $(d)$. The results were analyzed by Western blotting. (e) PARP-1 interaction of the ORF49 ${ }_{\text {KSHV }}$ mutant. FLAG-tagged ORF49 ${ }_{\mathrm{KSHV}}$ or ORF49 $9_{\mathrm{KSHV}} \Delta \mathrm{N}$ was transfected into HEK293T cells. The cells were harvested $48 \mathrm{~h}$ post-transfection and assayed for PARP-1 interaction by co-IP assays with an anti-PARP-1 antibody. The results were analyzed by Western blotting. 
According to its X-ray crystallographic structure, vPIP has a $\mathrm{V}$-shaped conformation consisting of $12 \alpha$-helices and characteristic $\mathrm{N}$-terminal $\beta$-strands $(\mathrm{N} \beta)$. Recently, the structure of ORF49 $_{\text {KSHV }}$ (PDB entry 5ipx) was reported to consist of 12 $\alpha$-helices with two pseudo-domains (Hew et al., 2017). The vPIP homologs of MHV-68 and KSHV share low sequence similarity $(\sim 20 \%)$, with an r.m.s. deviation of $2.2 \AA$ from $P y M O L$ and a $Z$ score of 24.5 from the DALI server (Holm \& Laakso, 2016), but they have highly similar structural configurations of multiple helices, despite the introduction of unexpected mutations in the ORF49 $9_{\mathrm{KSHV}}$ structure (Q140P and Q179E; Hew et al., 2017; Supplementary Fig. S3). These two proteins differ in that ORF49 $9_{\mathrm{KSHV}}$ has an $\mathrm{N}$-terminus with an $\alpha$-helix, whereas MHV-68 vPIP has an N-terminus with an $\mathrm{N} \beta$ (Supplementary Fig. S3). Moreover, although our structural and biochemical results indicate that MHV-68 vPIP forms a homodimer (Fig. 1), ORF49 $9_{\mathrm{KSHV}}$ does not exist as a dimer (Supplementary Fig. S4); this finding is consistent with a structural study of ORF49 $9_{\mathrm{KSHV}}$ (Hew et al., 2017). Nonetheless, the results from vPIP mutants suggest that dimerization is not required for PARP-1 interaction and RTA derepression, as shown by vPIP $\Delta \mathrm{C}$ : a mutant vPIP with intact function that does not form a dimer. Taken together, these results imply that homodimer formation by vPIP may be dispensable for vPIP function in RTA depression and PARP-1 interaction. Similar examples are seen in the cases of the translocation of ERK (Lidke et al., 2010) and the modulation of the CaV2.2 channel by the 14-3-3 protein (Li et al., 2007), where dimerization of ERK or 14-3-3 is dispensable for their function. However, it should be noted that vPIP dimerization may affect another function of vPIP which has not yet been elucidated.

A mutagenetic analyses based on the structural information revealed a critical domain and residues for vPIP function. Deletion of the $\mathrm{N}$-terminus including the $\alpha 1$ helix and $\beta$-strands (i.e. creation of the mutant protein vPIP $\Delta \mathrm{N}$ ) switched the subcellular localization of vPIP to 'cytoplasm only' (from the typical location in both the nucleus and cytoplasm) and severely impaired the function of this protein. These results suggest that the $\mathrm{N}$-terminus serves as a nuclear localization signal. Nevertheless, the sequence of the $\mathrm{N}$ terminus does not show any known or predicted nuclear localization signal when analyzed by prediction programs such as NucPred and Nuc-Ploc (Brameier et al., 2007; Shen \& Chou, 2007). To examine whether the defective function of vPIP $\Delta \mathrm{N}$ was owing to its exclusive localization in the cytoplasm, vPIP $\Delta \mathrm{N}$ was forced to express in the nucleus by tagging a classical NLS from the SV40 T antigen. However, its function was still defective in interaction with PARP-1 and/or RTA 1 (Supplementary Fig. S2). These results suggest that the $\mathrm{N}$-terminus not only serves as a nuclear localization signal but also plays a critical role in interacting with PARP-1, thereby interfering with the interaction between RTA and PARP-1. In contrast to vPIP $\Delta \mathrm{N}$, the vPIP mI mutant with alanine substitutions of Phe5, Ser12 and Thr16 is defective in function and in interaction with PARP-1, while maintaining an intact subcellular localization, suggesting that these three residues on the surface of vPIP are critical for its function and mechanism of action. The importance of these three residues was verified in the context of the viral genome, and it was found that the mutant virus vPIP $\mathrm{mI}$ shows weaker in vitro and in vivo replication, as does the vPIP-S virus, while the marker rescue virus (vPIP mI-MR) shows almost normal replication (Figs. 5 and 6). In addition to abated lytic replication, lower levels of latency in mice infected with the vPIP-S or vPIP mI virus were consistently observed; this effect may be owing to the inhibition of acute infection in the lungs (Fig. 6). Alternatively, this effect may be caused by the reduced ability of the vPIP-S or vPIP mI virus to establish latency in splenocytes or to efficiently reactivate from latently infected splenocytes. Nevertheless, these results highlight the importance of the inhibition of PARP-1 for viral fitness both in vitro and in vivo. To our knowledge, this is the first study to elucidate the molecular mechanism of action of any viral protein that regulates PARP-1 to promote viral replication.

In conclusion, we determined the X-ray crystallographic structure of vPIP, and structure-based mutagenesis experiments helped us to understand the viral strategy aimed at derepression of the inhibitory function of PARP-1 through a direct molecular interaction with vPIP, the mechanism of action of which is conserved between two oncogenic gammaherpesviruses.

\section{Funding information}

This work was supported by National Research Foundation Grants funded by the Korean Government (2012R1A1A2004532 and 2018R1A2B6001363 to M. J. Song and 2017R1A2B2005666 and 2018R1A44A1022589 to K. Y. Hwang).

\section{References}

Adams, P. D., Afonine, P. V., Bunkóczi, G., Chen, V. B., Davis, I. W., Echols, N., Headd, J. J., Hung, L.-W., Kapral, G. J., GrosseKunstleve, R. W., McCoy, A. J., Moriarty, N. W., Oeffner, R., Read, R. J., Richardson, D. C., Richardson, J. S., Terwilliger, T. C. \& Zwart, P. H. (2010). Acta Cryst. D66, 213-221.

Boussif, O., Lezoualc'h, F., Zanta, M. A., Mergny, M. D., Scherman, D., Demeneix, B. \& Behr, J.-P. (1995). Proc. Natl Acad. Sci. USA, 92, 7297-7301.

Brameier, M., Krings, A. \& MacCallum, R. M. (2007). Bioinformatics, 23, 1159-1160.

Bueno, M. T., Reyes, D., Valdes, L., Saheba, A., Urias, E., Mendoza, C., Fregoso, O. I. \& Llano, M. (2013). J. Virol. 87, 2496-2507.

Calderwood, M. A., Venkatesan, K., Xing, L., Chase, M. R., Vazquez, A., Holthaus, A. M., Ewence, A. E., Li, N., Hirozane-Kishikawa, T., Hill, D. E., Vidal, M., Kieff, E. \& Johannsen, E. (2007). Proc. Natl Acad. Sci. USA, 104, 7606-7611.

Chung, W.-C., Park, J.-H., Kang, H.-R. \& Song, M. J. (2015). J. Virol. 89, 9676-9682.

Dandri, M., Burda, M. R., Bürkle, A., Zuckerman, D. M., Will, H., Rogler, C. E., Greten, H. \& Petersen, J. (2002). Hepatology, 35, 217-223.

DeLano, W. L. (2001). PyMOL. http://www.pymol.org.

Gibson, B. A. \& Kraus, W. L. (2012). Nat. Rev. Mol. Cell Biol. 13, 411424.

González, C. M., Wong, E. L., Bowser, B. S., Hong, G. K., Kenney, S. \& Damania, B. (2006). J. Virol. 80, 3062-3070. 
Grady, S. L., Hwang, J., Vastag, L., Rabinowitz, J. D. \& Shenk, T. (2012). J. Virol. 86, 8259-8268.

Gupte, R., Liu, Z. \& Kraus, W. L. (2017). Genes Dev. 31, 101-126.

Gwack, Y., Nakamura, H., Lee, S. H., Souvlis, J., Yustein, J. T., Gygi, S., Kung, H. J. \& Jung, J. U. (2003). Mol. Cell. Biol. 23, 8282-8294.

Ha, H. C., Juluri, K., Zhou, Y., Leung, S., Hermankova, M. \& Snyder, S. H. (2001). Proc. Natl Acad. Sci. USA, 98, 3364-3368.

Hew, K., Veerappan, S., Sim, D., Cornvik, T., Nordlund, P. \& Dahlroth, S.-L. (2017). J. Virol. 91, e01947-16.

Holm, L. \& Laakso, L. M. (2016). Nucleic Acids Res. 44, W351-W355.

Hong, G. K., Delecluse, H.-J., Gruffat, H., Morrison, T. E., Feng, W.-H., Sergeant, A. \& Kenney, S. C. (2004). J. Virol. 78, 4983-4992.

Kameoka, M., Nukuzuma, S., Itaya, A., Tanaka, Y., Ota, K., Inada, Y., Ikuta, K. \& Yoshihara, K. (2005). Biochem. Biophys. Res. Commun. 334, 412-417.

Kameoka, M., Tanaka, Y., Ota, K., Itaya, A. \& Yoshihara, K. (1999). Biochem. Biophys. Res. Commun. 262, 285-289.

Kim, M. Y., Zhang, T. \& Kraus, W. L. (2005). Genes Dev. 19, 19511967.

Ko, H. L. \& Ren, E. C. (2011). Hepatology, 54, 1190-1198.

Ko, H. L. \& Ren, E. C. (2012). Biomolecules, 2, 524-548.

Lee, S., Cho, H.-J., Park, J.-J., Kim, Y.-S., Hwang, S., Sun, R. \& Song, M. J. (2007). J. Virol. 81, 9870-9877.

Li, Y., Wu, Y., Li, R. \& Zhou, Y. (2007). Channels, 1, 1-2.

Lidke, D. S., Huang, F., Post, J. N., Rieger, B., Wilsbacher, J., Thomas, J. L., Pouysségur, J., Jovin, T. M. \& Lenormand, P. (2010). J. Biol. Chem. 285, 3092-3102.

Lukac, D. M., Kirshner, J. R. \& Ganem, D. (1999). J. Virol. 73, 93489361.

Lukac, D. M., Renne, R., Kirshner, J. R. \& Ganem, D. (1998). Virology, 252, 304-312.

Luo, X. \& Kraus, W. L. (2012). Genes Dev. 26, 417-432.

Lupey-Green, L. N., Moquin, S. A., Martin, K. A., McDevitt, S. M., Hulse, M., Caruso, L. B., Pomerantz, R. T., Miranda, J. L. \& Tempera, I. (2017). Virology, 507, 220-230.

Martin, K. A., Lupey, L. N. \& Tempera, I. (2016). J. Virol. 90, 8520 8530.
Mattiussi, S., Tempera, I., Matusali, G., Mearini, G., Lenti, L., Fratarcangeli, S., Mosca, L., D'Erme, M. \& Mattia, E. (2007). Infect. Agent. Cancer, $2,18$.

Ng, Y. C., Chung, W.-C., Kang, H.-R., Cho, H.-J., Park, E.-B., Kang, S.-J. \& Song, M. J. (2018). Nucleic Acids Res. 46, 9011-9026.

Noh, C.-W., Cho, H.-J., Kang, H.-R., Jin, H. Y., Lee, S., Deng, H., Wu, T.-T., Arumugaswami, V., Sun, R. \& Song, M. J. (2012). J. Virol. 86, 1109-1118.

Ohsaki, E., Ueda, K., Sakakibara, S., Do, E., Yada, K. \& Yamanishi, K. (2004). J. Virol. 78, 9936-9946.

Rickabaugh, T. M., Brown, H. J., Wu, T.-T., Song, M. J., Hwang, S., Deng, H., Mitsouras, K. \& Sun, R. (2005). J. Virol. 79, 32173222 .

Rom, S., Reichenbach, N. L., Dykstra, H. \& Persidsky, Y. (2015). Front. Microbiol. 6, 878.

Rouleau, M., Patel, A., Hendzel, M. J., Kaufmann, S. H. \& Poirier, G. G. (2010). Nat. Rev. Cancer, 10, 293-301.

Shen, H.-B. \& Chou, K.-C. (2007). Protein Eng. Des. Sel. 20, 561567.

Sun, R., Lin, S.-F., Gradoville, L., Yuan, Y., Zhu, F. \& Miller, G. (1998). Proc. Natl Acad. Sci. USA, 95, 10866-10871.

Tempera, I., Deng, Z., Atanasiu, C., Chen, C.-J., D'Erme, M. \& Lieberman, P. M. (2010). J. Virol. 84, 4988-4997.

Tischer, B. K., von Einem, J., Kaufer, B. \& Osterrieder, N. (2006). Biotechniques, 40, 191-197.

Trathnigg, B. (1995). Prog. Polym. Sci. 20, 615-650.

Wang, Y., Li, H., Tang, Q., Maul, G. G. \& Yuan, Y. (2008). J. Virol. 82, 2867-2882.

Winn, M. D., Ballard, C. C., Cowtan, K. D., Dodson, E. J., Emsley, P., Evans, P. R., Keegan, R. M., Krissinel, E. B., Leslie, A. G. W., McCoy, A., McNicholas, S. J., Murshudov, G. N., Pannu, N. S., Potterton, E. A., Powell, H. R., Read, R. J., Vagin, A. \& Wilson, K. S. (2011). Acta Cryst. D67, 235-242.

Yu, D., Ellis, H. M., Lee, E.-C., Jenkins, N. A., Copeland, N. G. \& Court, D. L. (2000). Proc. Natl Acad. Sci. USA, 97, 5978-5983.

Zhang, Z., Hildebrandt, E. F., Simbulan-Rosenthal, C. M. \& Anderson, M. G. (2002). Virology, 296, 107-116. 